\title{
Lysophosphatidic Acid Receptor Agonism: Discovery of Potent Nonlipid Benzofuran Ethanolamine Structures $\$$
}

\author{
Etienne Guillot, Jean-Christophe Le Bail, Pascal Paul, Valérie Fourgous, Pascale Briand, \\ Michel Partiseti, Bruno Cornet, Philip Janiak, and Christophe Philippo \\ Diabetes and Cardiovascular Unit, Sanofi R\&D, Chilly-Mazarin, France (E.G., J.C.L.B., P.B., P.J.); Global Research Portfolio and \\ Project Management, Sanofi R\&D, Chilly-Mazarin, France (C.P.); Translational Science Unit, Sanofi R\&D, Chilly-Mazarin, France \\ (P.P., V.F.); In-silico design, Chilly-Mazarin, France (B.C.); and Integrated Drug Discovery, Sanofi R\&D, Vitry-Sur-Seine, France \\ (M.P.)
}

Received January 30, 2020; accepted May 11, 2020

\begin{abstract}
Lysophosphatidic acid (LPA) is the natural ligand for two phylogenetically distinct families of receptors $\left(\mathrm{LPA}_{1-3}, \mathrm{LPA}_{4-6}\right)$ whose pathways control a variety of physiologic and pathophysiological responses. Identifying the benefit of balanced activation/repression of LPA receptors has always been a challenge because of the high lability of LPA and the limited availability of selective and/or stable agonists. In this study, we document the discovery of small benzofuran ethanolamine derivatives (called $\mathrm{CpX}$ and $\mathrm{CpY}$ ) behaving as $\mathrm{LPA}_{1-3}$ agonists. Initially found as rabbit urethra contracting agents, their elusive receptors were identified from ${ }^{35}$ S]GTP $\gamma$ S-binding and $\beta$-arrestin2 recruitment investigations and then confirmed by $\left[{ }^{3} \mathrm{H}\right] \mathrm{CpX}$ binding studies (urethra, hLPA ${ }_{1-2}$ membranes). Both compounds induced a calcium response in $\mathrm{hLPA} \mathrm{A}_{1-3}$ cells within a range of $0.4-1.5$-log lower potency as compared with LPA. The contractions of rabbit urethra strips induced by these compounds perfectly matched binding affinities with values reaching the two-digit nanomolar level. The antagonist, KI16425, dose-dependently antagonized $\mathrm{CpX}$-induced contractions in agreement with its affinity profile $\left(\mathrm{LPA}_{1} \geq \mathrm{LPA}_{3}>>\mathrm{LPA}_{2}\right)$. The most
\end{abstract}

potent agonist, $\mathrm{CpY}$, doubled intraurethral pressure in anesthetized female rats at $3 \mu \mathrm{g} / \mathrm{kg}$ i.v. Alternatively, $\mathrm{CpX}$ was shown to inhibit human preadipocyte differentiation, a process totally reversed by KI16425. Together with original molecular docking data, these findings clearly established these molecules as potent agonists of $\mathrm{LPA}_{1-3}$ and consolidated the pivotal role of $\mathrm{LPA}_{1}$ in urethra/prostate contraction as well as in fat cell development. The discovery of these unique and less labile $\mathrm{LPA}_{1-3}$ agonists would offer new avenues to investigate the roles of LPA receptors.

\section{SIGNIFICANCE STATEMENT}

We report the identification of benzofuran ethanolamine derivatives behaving as potent selective nonlipid $\mathrm{LPA}_{1-3}$ agonists and shown to alter urethra muscle contraction or preadipocyte differentiation. Unique at this level of potency, selectivity, and especially stability, compared with lysophosphatidic acid, they represent more appropriate tools for investigating the physiological roles of lysophosphatidic acid receptors and starting point for optimization of drug candidates for therapeutic applications.

\section{Introduction}

Lysophosphatidic acid (LPA) is a bioactive phospholipid principally generated at lipoprotein or membrane levels through the enzymatic hydrolysis of lysophospholipids by autotaxin (ATX) (Yung et al., 2014). LPA exists in different forms (16:0-, 18:2-, 18-1, 16:1-LPA being the most frequent), is ubiquitously distributed, is present in interstitial fluids, and circulates in plasma at concentrations that could reach micromolar levels. Over the last few decades, extremely various physiologic and pathophysiological roles have been evidenced for LPA (Choi et al., 2010), ranging from cellular proliferation to contraction of muscle tissues. To date, LPA has been shown to bind and activate six G-protein-coupled LPA

https://doi.org/10.1124/jpet.120.265454.

S This article has supplemental material available at jpet.aspetjournals.org. receptors (LPAR): the closely related receptors $\mathrm{LPA}_{1}-\mathrm{LPA}_{2}-$ $\mathrm{LPA}_{3}$, which belong to the endothelial differentiation gene (EDG) family, and $\mathrm{LPA}_{4}-\mathrm{LPA}_{5}-\mathrm{LPA}_{6}$, which belong to the phylogenetically distant non-EDG family (Yung et al., 2014). Even if the nature of receptor activation may vary with the LPA form, the fine tuning of the various biologic responses probably stems from heterogeneity of LPAR expression in tissues and species and from the ability of individual receptors to couple to several distinct heterotrimeric G-proteins, each driving its own effector cascade. Additionally, the strong metabolic instability of LPA and its resultant very short half-life (Salous et al., 2013), together with its rapid de novo production by ATX (Saga et al., 2014), creates a serious risk of bias during functional characterization of exogenous LPA. Consequently, identification and understanding of the right LPAR combination controlling a specific biologic response remains challenging, even if specific genetic deletions have clarified some points (Choi et al., 2008).

ABBREVIATIONS: ATX, autotaxin; CpX, (2R)-2-(diethylamino)-2-(2,3-dimethylbenzofuran-7-yl)ethanol; CpY, (2R)-2-(diethylamino)-2-(2-ethyl-3methyl-benzofuran-7-yl)ethanol; $\mathrm{DE}_{50 \%}$, doses increasing by $50 \%$ the baseline urethral pressure; EDG, endothelial differentiation gene; GPCR, G-protein-coupled receptor; hLPA, human LPA; IUP, intraurethral pressure; LPA, lysophosphatidic acid; LPAR, LPA receptors; MAP, mean arterial pressure; $\mathrm{pEC}_{50},-\log _{10}\left(\mathrm{EC}_{50}\right)$; S1P, Sphingosine-1-phosphate receptor; TM, transmembrane domain. 
For all these reasons, search of more selective, potent, and stable LPA-mimicking structures is needed to better explore the therapeutic potential of LPA/LPAR pathways. As of today, this search was hampered by the hydrophobic nature of the ligand pocket of LPAR (Chrencik et al., 2015).

In the early 2000s, the first LPAR antagonists such as KI16425 from Kirin were discovered (Ohta et al., 2003). KI16425 keeps a short aliphatic tail and has been shown to display a selective antagonistic profile $\left(\mathrm{LPA}_{1} \geq \mathrm{LPA}_{3}>>\mathrm{LPA}_{2}\right)$ toward LPA responses. More recently, new nonlipid antagonist structures have demonstrated improved potency and sometimes better selectivity for single LPAR (Fells et al., 2008; Kihara et al., 2015; Sakamoto et al., 2018), such as the specific LPA 1 antagonists, SAR100842 or BMS-986020, which are currently being investigated in patients with systemic sclerosis or idiopathic pulmonary fibrosis. In contrast, limited progress has been made in appreciating the potential therapeutic value of selective LPAR agonists beyond a few preclinical studies (Choi et al., 2010), which have suggested, for instance, the potential of LPA mimetics to reduce the development of human nutritional obesity (Rancoule et al., 2014). The ability of LPA to increase intraurethral pressure in rats (Terakado et al., 2016) also suggests that LPA mimetics could represent a therapeutic alternative to increase urethral pressure closure and avoid unintentional leaks of urine, the main problem of female stress incontinence (Malallah and Al-Shaiji, 2015). Several lipid-based agonists, derivatives of LPA, such as 1-oleoyl- 2-Omethyl-rac-glycerophosphothioate (OMPT) (Qian et al., 2003) or its alkyl forms (Qian et al., 2006), gained specificity for $\mathrm{LPA}_{3}$ but displayed only moderate improvement of metabolic stability. More recently, the glycidol derivative (S)-17 (UCM-05194) displayed selective LPA 1 interaction (González Gil et al., 2020). Among few nonlipid structures, GRI977143 has been identified through virtual screening by using a $\mathrm{LPA}_{1}$ pharmacophore and has been characterized as a selective but weak $\mathrm{LPA}_{2}$ agonist $\left(\mathrm{EC}_{50} \sim 10 \mu \mathrm{M}\right)$ (Kiss et al., 2012). Few specific nonlipid $\mathrm{LPA}_{3}$ modulators displaying activity close to micromolar range have also been patented (Shankar et al., 2003). To our knowledge, no potent nonlipid $\mathrm{LPA}_{1-3}$ agonist has been reported. All in all, identification of new potent and more stable drug-like agonist compounds would be very useful to explore and consolidate on the potential therapeutic benefits of selective LPAR agonists.

In this study, we report the identification of benzofuran ethanolamine derivatives, initially discovered as orphan receptor smooth muscle contracting agents and behaving as selective and potent agonists of LPAR. Representatives of the chemical series, CpX and analogs, were profiled for cellular, binding, and pharmacological responses in various biologic models. Our results show that these molecules are strong binders of $\mathrm{LPA}_{1-2}$ and potent contractant of urethra, acting unambiguously on $\mathrm{LPA}_{1}$. Additional cellular calcium-based responses enlarged their agonistic pattern to $\mathrm{LPA}_{3}$. Additionally, these agonists behave as inhibitors of human preadipocyte differentiation by activating $\mathrm{LPA}_{1}$. These selective nonlipid $\mathrm{LPA}_{1-3}$ agonists represent excellent tools for deciphering LPA pathways and a unique starting point for optimization of drug candidates for new therapeutic applications.

\section{Materials and Methods}

Test Compounds. The benzofuran ethanolamine derivatives (2R)-2-(diethylamino)-2-(2,3-dimethylbenzofuran-7-yl)ethanol ( $\mathrm{CpX}$ ), its close analog (2R)-2-(diethylamino)-2-(2-ethyl-3-methyl-benzofuran-7-yl)ethanol (CpY) (Fig. 1), and several related structures such as $\mathrm{CpZ}_{1}$ to $\mathrm{CpZ}_{4}$ (Fig. 7) were synthesized following described procedures by the chemistry department of Sanofi (France) as well as the $\mathrm{LPA}_{1} / \mathrm{LPA}_{3}$-specific antagonist Kirin KI16425 (Ohta et al., 2003) and the specific $\mathrm{LPA}_{3}$ antagonists (Ceretek Cpd 701/Cpd 705, Shankar et al., 2003). Radiolabeled $\left[{ }^{3} \mathrm{H}\right] \mathrm{CpX}$ was synthesized by Amersham (30 $\mathrm{Ci} / \mathrm{mmol})$. The general synthetic route to benzylamine derivatives $\left(\mathrm{CpX}, \mathrm{CpY}, \mathrm{CPZ}_{3}\right)$ described in this report includes three key sequences. First, a suitably substituted benzofuran derivative is prepared by cyclodehydratation in cold sulfuric acid. For instance, treatment of 3-(2-bromo-phenoxy)-2-butanone under those conditions yields to 2,3-dimethyl-7-bromo-benzofuran. Then, the bromide atom at the position 7 of benzofuran is converted to a chiral 1,2 ethanediol side chain found on intermediate $\mathrm{CpZ}_{4}$. This second sequence is performed by a Stille cross-coupling reaction using tributylvinyltin followed by an enantioselective Sharpless dihydroxylation on vinyl benzofurans (Philippo et al., 2000). AD-mix $\alpha$ is used to deliver the more potent isomer. Finally, the amine is introduced by selective protection of the primary alcohol with a bulky group, such as tertbutyldimethylsilylchloride, followed by mesylation of the secondary alcohol and subsequent displacement by a secondary amine, such as diethylamine. This last step results in an inversion of the chiral center. Finally, the protecting group is removed to allow access to compound $\mathrm{CpX}$ or $\mathrm{CpY}$, according to starting benzofuran moiety used. In the case of ethanolamine derivatives $\left(\mathrm{CpZ}_{1}, \mathrm{CpZ}_{2}\right)$, only the third sequence is slightly modified. The primary alcohol is not protected but converted by using tosyl chloride in a leaving group that is substituted by diethylamine. The reaction mixture mostly yields ethanolamines but is contaminated by a very small amount of benzylamines that is readily removed by chromatography on silica gel. Regioselectivity of this nucleophilic substitution evidenced generation of an epoxide as reaction intermediate. All derivatives but $\mathrm{CpZ}_{4}$ were converted into hydrochloride salts, recrystallized, and fully characterized (Philippo et al.,1998a,b). Oleoyl-LPA (Cayman, ref 62215) was used in studies conducted by Eurofins Pharma Discovery/Cerep.

Tissue Samples. Urethras from female pigs (Large White Landrace, $110 \mathrm{~kg}$; Lebeaux, Gambais, France), Sprague-Dawley rats (150-300 g; Iffa Credo, France), New Zealand rabbits (3 to $4 \mathrm{~kg}$ ), and beagle dogs (10-12 kg) (CEDS, Mezilles, France) were used in muscle contraction assays. Brains from Sprague-Dawley rats were also used. Human prostatic samples were obtained from patients undergoing transvesical adenomectomy (Institut Mutualiste Montsouris, Paris) in the context of benign prostatic hypertrophy. Human adipose tissue was obtained from female patients undergoing liposuction procedures under local anesthesia (Clinique Alphand, Paris). All subjects gave their informed consent for tissue sampling.

Cell Samples: LPAR Recombinant Cells and Human Urethra Smooth Muscle Cells. To prepare membranes for binding studies, Chinese Hamster Ovary (CHO) dihydrofolate-reductase-negative cells were transfected with vectors derived from plasmid 658 carrying the supplementary 13-amino acid NH2-terminal C-myc and the cDNA encoding for the human $\mathrm{LPA}_{1-2}, \mathrm{~S}_{3} \mathrm{P}_{3}$, and $\mathrm{S}_{1} \mathrm{P}_{4}$ receptors (Miloux and Lupker., 1994, Shire et al., 1996). Stably transformed cell lines were
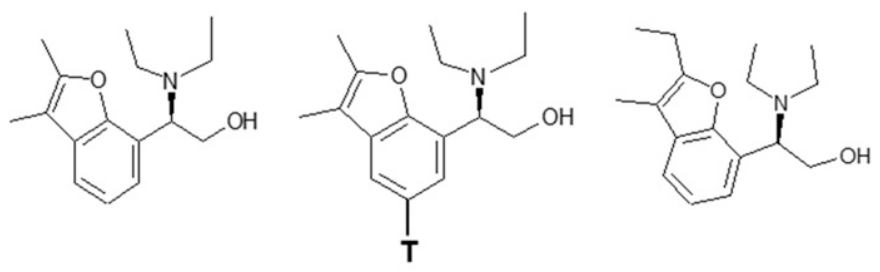

$$
\mathrm{CpX}
$$

$\left[{ }^{3} \mathrm{H}\right] \mathrm{CpX}$

CpY

Fig. 1. Chemical structures of benzofuran ethanolamine derivatives $\mathrm{CpX}$, $\left[{ }^{3} \mathrm{H}\right] \mathrm{CpX}$, and $\mathrm{CpY}$. 
isolated as previously described (Miloux and Lupker, 1994; Serradeil-Le Gal et al., 2000). They were grown in $10 \mathrm{mM}$ HEPES, pH 7.4, minimal essential medium supplemented with $5 \%$ FBS, and $8 \mathrm{~g} / \mathrm{l}$ sodium bicarbonate and $300 \mu \mathrm{g} / \mathrm{ml}$ geneticin at $37^{\circ} \mathrm{C}$ in a humidified atmosphere containing $5 \% \mathrm{CO}_{2}$. Wild-type $\mathrm{CHO}$ cells were routinely grown in a similar culture medium. Calcium mobilization was investigated in Chem- 1 cells expressing $\mathrm{LPA}_{1}$ and CHO-K1 cells expressing $\mathrm{LPA}_{2}$ or $\mathrm{LPA}_{3}$ and operated by Eurofins Pharma Discovery/Cerep, France (catalogue reference 4374, 3171, and 3158, respectively). Cells were loaded with a fluorescent probe (Fluo4/8) and responses monitored with a FLIPR Tetra (molecular device). For the $\beta$-arrestin2 recruitment screening campaign, transformed African green monkey kidney fibroblast (COS-7) cells were transiently cotransfected in 96-well plate format with plasmids (p312) encoding individual tested G-protein coupled receptor (GPCR), including LPAR and $\beta$-arrestin2-GFP, and then refed with serum-free medium 36 hours after transfection. Tested compounds were incubated for 20 minutes and fixed before GFP signal distribution while being monitored by fluorescence microscopy. Human urethra smooth muscle cells were purchased from CloneticsBioWhittaker (Venders, Belgium) and were grown at $37^{\circ} \mathrm{C}$ in Smooth muscle cell growth Basal Medium medium supplemented with smooth muscle cell growth factors (SingleQuotes; BioWhittaker), FBS (10\%), and antibiotics. Culture medium was removed every other day, and cells were subcultured by treatment with $0.05 \%$ trypsin and $0.02 \%$ EDTA.

Expression of $\mathbf{L P A}_{1-3}$. In human adipocytes and prostate, mRNA abundance was estimated by TaqMan analysis (Applied Biosystems) by using the following commercial probes: Hs00173500_m1 ( $\left.\mathrm{LPA}_{1}\right)$, Hs00173704_m1 $\left(\mathrm{LPA}_{2}\right)$, and Hs00173857_m1 $\left(\mathrm{LPA}_{3}\right)$.

Membrane Binding Assays. Tissues or cells were homogenized on ice in Tris- $\mathrm{HCl}$ buffer ( $5 \mathrm{mM}$, $\mathrm{pH}$ 7.4) containing protease inhibitors (aprotinin $10 \mu \mathrm{g} / \mathrm{ml}$, Phenylmethylsulfonyl fluoride $0.2 \mathrm{mM}$, and benzamidine $0.83 \mathrm{mM}$ ). The resultant homogenate was centrifuged at $4350 \mathrm{~g}$ for 10 minutes at $4^{\circ} \mathrm{C}$, and then the supernatant was filtered and centrifuged at $48,400 \mathrm{~g}$ for 1 hour at $4^{\circ} \mathrm{C}$. The pellet was frozen at $-80^{\circ} \mathrm{C}$ until the binding experiment. Protein concentration was determined by the Bradford method. Thawed membranes were diluted in Tris-HCl buffer (50 mM pH 7.4) and incubated for 1 hour 1) with an increasing concentration of $\left[{ }^{3} \mathrm{H}\right] \mathrm{CpX}$ for saturation experiments or 2) for displacement studies with the indicated concentration of $\left[{ }^{3} \mathrm{H}\right] \mathrm{CpX}$ and increasing concentrations of test compounds. Nonspecific binding was determined in the presence of $10 \mu \mathrm{M}$ cold $\mathrm{CpX}$. The reactions were stopped by rapid filtration on polyethyleneimine $0.5 \%$ pretreated filters ( $\mathrm{GF} / \mathrm{C}$ or filtermat $\mathrm{A})$; then, filters were washed, and the signal was determined by scintillation (Perkin Elmer counters).

$\left[{ }^{35}\right.$ S $]$ GTP $\gamma$ S Binding Assay on Brain Slices. Sprague-Dawley brains were quickly removed by dissection and frozen on dry ice. The tissues were cut on a HM500 cryostat (Microm, France) to obtain $12-\mu \mathrm{m}$ sections that were dehydrated at $4^{\circ} \mathrm{C}$ under vacuum overnight before storage at $-80^{\circ} \mathrm{C}$. Sections were equilibrated for 10 minutes at $25^{\circ} \mathrm{C}$ in Tris-buffer (50 mM Tris-HCI, $3 \mathrm{mM} \mathrm{MgCl} 2,0.2 \mathrm{mM}$ EGTA, $100 \mathrm{mM} \mathrm{NaCl} \mathrm{pH} \mathrm{7.4)} \mathrm{and} \mathrm{then} \mathrm{for} 15$ minutes at $25^{\circ} \mathrm{C}$ in Tris-buffer supplemented with GDP $(2 \mathrm{mM})$. The sections were finally incubated for 2 hours at $25^{\circ} \mathrm{C}$ in Tris-buffer $2 \mathrm{mM}$ GDP supplemented with $\left[{ }^{35} \mathrm{~S}\right]$ GTP $\gamma \mathrm{S}$ (0.05 nM) (Amersham). Agonist stimulated binding was measured in the presence of $1 \mu \mathrm{M} \mathrm{CpX}$ or $\mathrm{CpY}$, and nonspecific binding was determined in the presence of nonlabeled GTP $\gamma \mathrm{S}$ (10 $\mu \mathrm{M})$ (Sigma). Sections were washed twice with Tris-HCl $(50 \mathrm{mM}) \mathrm{pH}$ 7.0 at $4^{\circ} \mathrm{C}$, dipped in water, and air dried. Sections were exposed to autoradiography hyperfilm Beta-max (Amersham) in a x-Omatic closed cassette (Kodak).

Preadipocyte Differentiation Assay. Liposuctions were digested with collagenase, filtered, and centrifuged. The pellet obtained was resuspended in $\mathrm{NH}_{4} \mathrm{Cl}(160 \mathrm{mM})$ to lyse contaminating red blood cells. Preadipocytes were then collected by centrifugation and filtered through a sterile $100-\mu \mathrm{m}$ nylon mesh to remove cellular debris. Cells were frozen at $-80^{\circ} \mathrm{C}$ until further use. For differentiation into adipocytes, thawed cells were grown for 5 days in Dulbecco's modified
Eagle's medium $1 \mathrm{~g} / \mathrm{l}$ glucose (Gibco) and 10\% FBS (Gibco) until nearly confluent. Then, after trypsination and plating in a 24 -well format, cells were allowed to differentiate with test compounds, 6 days in a medium (Zenbio, AM-1, containing $33 \mu \mathrm{M}$ biotin, $17 \mu \mathrm{M}$ pantothenate, $100 \mathrm{mM}$ human insulin, $1 \mu \mathrm{M}$ dexamethasone), complemented with 3-isobutyl1-methylxanthine $(0.25 \mathrm{mM}$; Sigma). Fresh medium and test compounds were changed on the 3rd day. Stock solutions of $\mathrm{CpX}$ and $\mathrm{KI} 16425$ (10 $\mathrm{mM}$ to $1 \mu \mathrm{M}$ ) were prepared in DMSO and diluted in medium (1000-fold). Controls were exposed to the same dilution of DMSO. Cells being differentiated were then harvested, suspended in Laemmli buffer (Bio-Rad), and boiled for 10 minutes. Protein lysates were quantified by BCA assay (Pierce) and $25-50 \mu \mathrm{g}$ of protein mixture adjusted to 0.1 M DTT (Invitrogen) and were submitted to electrophoresis on Criterion Bis-Tris 4\%-12\% Pre-Cast Gel (Bio-Rad). Separated proteins were transferred onto polyvinylidene fluoride membranes (BioRad), blocked in low-fat milk powder (10\% w/v) in PBS-0.05\% Tween-20, and probed with the primary antibodies anti-perilipin (ref 29; Progen), anti-adiponectin (ref 611644; BD transduction laboratories), and anti$\beta$-actin (ref A5441; Sigma). After washing, membranes were incubated with Protein A peroxidase (ZYMED) for perilipin, adiponectin, and horseradish peroxidase-conjugated antibody for $\alpha$-actin (Jackson Immuno Research). After final wash, immunoreactive bands were detected with ECL kit (Biorad), using hyperfilm ECL (Amersham). Western blot bands were quantified by Genesys software (G:box Chemi-XL1; Syngene, England) and normalized with beta-actin signal by using Gene Tools software (Syngene) to estimate $\mathrm{CpX}$ $\mathrm{pEC}_{50}$ and $\mathrm{KI} 16425 \mathrm{pA}_{2}$.

Contraction of Isolated Tissues. Smooth muscle strips were mounted in organ baths containing a modified Krebs solution in the presence of $1 \mu \mathrm{M}$ propranolol to block $\beta$-adrenoceptors. The Krebs solution was maintained at $37^{\circ} \mathrm{C}$ and oxygenated with a mixture of $95 \% \mathrm{O}_{2}$ and $5 \% \mathrm{CO}_{2}$. After a stabilization time of 60 minutes, tissues were contracted with $30 \mu \mathrm{M}$ norepinephrine followed by phenylephrine $(100 \mu \mathrm{M})$ after 30 minutes of washing. After an additional 30 minutes of washing and a new stabilization period, a concentration-response curve of $\mathrm{CpX}$ was performed on each tissue. The contractile potency of structurally related analogs of $\mathrm{CpX}$ as well as KI16425 potency (1-3-10 $\mu \mathrm{M})$ to shift CpX-induced contraction were also investigated in rabbit urethra. Results are expressed as percentage of the response to phenylephrine.

Protocol for Measurement of Urethral Pressure in Anesthetized Rats. Female Sprague-Dawley rats (Charles River, France) weighing between 350 and $400 \mathrm{~g}$ on the day of surgery and having had at least three litters were anesthetized with pentobarbital $(15 \mathrm{mg} / \mathrm{kg}$ i.p.) and ketamine (20 mg/kg i.p.) for surgery. The abdominal artery and the femoral vein were catheterized, respectively, for blood pressure measurement and intravenous injection of test compounds or vehicle. After laparotomy, the urethra and the urinary bladder were exposed, and a catheter was introduced by an incision at the level of the bladder neck and positioned into the urethra for a length of approximately $1.3 \mathrm{~cm}$. The urethra was continuously infused with saline at a temperature of $37^{\circ} \mathrm{C}$ and at a rate of $0.5 \mathrm{ml} / \mathrm{h}$. Arterial and urethral pressures were measured together with heart rate and continuously recorded and analyzed by dedicated software (MacLab). After a stabilization period of 20 minutes to record basal values, the first drug administration was operated along a 5-minute perfusion ( $1 \mathrm{ml}$ i.v. of solution). Then, four successive doses of the drug were administered every 15 minutes. In case of the absence of a urethral response, an intravenous injection of phenylephrine was given 10 minutes after the last dose of the compound. Absence of a urethral response to phenylephrine was an exclusion criterion for the animal. At the end of the experiment, animals were sacrificed by a lethal dose of pentobarbital. This study was performed in agreement with European Union directives for the standard of care and use of laboratory animals and approved by the animal care and use committee of Sanofi R\&D. For pharmacokinetic complement, blood samples were collected after administration of $\mathrm{CpY}(1 \mathrm{mg} / \mathrm{kg}$ i.v. $)$ in rats. Plasma was extracted with acetonitrile and centrifuged, and $\mathrm{CpY}$ 
concentrations were determined by liquid chromatography-tandem mass spectrometry.

Data Analysis. Results are expressed as means \pm S.D. Agonistbinding affinities were determined by nonlinear regression using iterative fitting procedures (Sigma Plot software) and expressed as $K_{D}$ (affinity constant) and Bmax (maximum binding) during saturation experiments $\left(\mathrm{B}=\mathrm{Bmax} \mathrm{X}[\mathrm{L}] /\left(\mathrm{K}_{\mathrm{D}}+[\mathrm{L}]\right)\right.$; or alternatively, during displacement studies, they were determined by $-\log _{10}(\mathrm{Ki})(\mathrm{pKi})$, using the Cheng-Prussof formula $\mathrm{Ki}=\mathrm{IC}_{50} /\left(1+[\mathrm{L}] / \mathrm{K}_{\mathrm{D}}\right)$, where $\mathrm{L}$ is the concentration of ligand. Agonist potency to contract tissues were determined by nonlinear regression, using iterative fitting procedures (Sigma Plot software) and expressed as $\left[-\log _{10}\left(\mathrm{EC}_{50}\right)\right], \mathrm{pEC}_{50}$. Antagonist apparent affinity was expressed as $\mathrm{PK}_{\mathrm{B}}$ determined from Schild Plot analysis (slope statistically not different from 1) or $\mathrm{pA}_{2}$ (estimated affinity from one single antagonist concentration effect) determined by the formula $\left[-\log _{10}([\mathrm{~B}] / \mathrm{CR}-1)\right]$, where $\mathrm{B}$ is the concentration of the antagonist, and $\mathrm{CR}$ is the ratio $\mathrm{IC}_{50} \mathrm{with} / \mathrm{IC}_{50}$ without antagonist. In in vivo studies, statistical significances were determined by one-way repeated measures analysis of variance followed by a Dunnett post hoc test (SAS 9.4 software). Urethral pressure was converted as percent of baseline, and doses increasing by $50 \%$ the baseline urethral pressure $\left(\mathrm{DE}_{50 \%}\right)$ were estimated from linear regression (Sigma Plot software).

Molecular Modeling. For GPCR transmembrane domain (TM) identification, reference alignments were made as published by Bissantz et al. (2004), with a representative panel of GPCRs, giving residue type probabilities at each TM position. Then, the target sequence was slid over the reference alignment to obtain the best sum of probabilities for each TM. This method was applied successfully to assign all TMs of $\mathrm{LPA}_{1-3}$ except for TM5, for which low scores and very low differences between the first and second scores were obtained. In addition, proline was absent in the TM5 anchor position, and we observed incomplete Baldwin invariants (Baldwin, 1993) as well as no consensus sequence. We therefore noted a difference encountered in X-ray structures of EDG family members (no helix kink and a shift of $\sim 5 \AA$ of the anchor residue), yielding different molecular environments for the helix portion and thus different sequences that would explain this low scoring. Therefore, because of this unsuccessful assignation, $\mathrm{LPA}_{1}$ antagonist X-ray structure (pdb id: 4z34, Chrencik et al., 2015) and LxMVxxYxxI invariant sequence position (Baldwin, 1993) were preferentially used to obtain a better high-quality level TM5 assignation. For an easier comparison between GPCR, Ballesteros-Weinstein numbering was used (Ballesteros and Weinstein, 1995). Starting with the activated conformation structure CNR1_HUMAN (PDB:5xr8) as a template, an automated modelbuilding procedure was used, as proposed by Nilges and Brünger (1991), in which the remaining backbone and side chain atoms were only built with packing and stereochemical restraints by using a furnished XPLOR script (Brünger et al., 1998; Nilges et al., 1988a,b). Ligand preparation was done with the LigPrep module for energy minimization (with the OPLS-2005 force field) and charge assignment (Schrodinger release 2019-4, LLC, New-York). Docking calculations were performed by using Glide SP (Friesner et al., 2004; Halgren et al., 2004). The docking region (grid) was centered on the template ligand in the model with default box sizes. Flexible ligands were docked by Glide into a rigid receptor structure by sampling of the conformational, orientational, and positional degrees of freedom of the ligand, generating many conformations for a ligand followed by a series of hierarchical filters to enable rapid evaluation of ligand poses.

\section{Results}

\section{Initial Deciphering Investigations and Selectivity}

$\mathrm{CpX}$ and related compounds were initially discovered as rabbit urethra smooth muscle contracting agents, but associated receptors were not identified. First, modulators of classic pathways (intra-/extracellular) known to potentially alter smooth muscle contraction were tested but found inactive. For example, among the $\sim 70$ reference molecules tested, antagonists for $\alpha$ - and $\beta$-adrenergic, histamine, dopamine, cholinergic, and neurokinin receptors failed to reduce $\mathrm{CpX}$ induced rabbit urethra contraction (Supplemental Table 1). Only nonspecific molecules inducing calcium depletion such as caffeine impaired the contraction.

$\mathrm{CpX}$ was radiolabeled and binding sites were clearly identified in the urethra membranes (see below) but also in membranes from other tissues, including the brain. By using this binding assay, more than 650 molecules targeting different pathways were tested and found inactive in displacing $\left[{ }^{3} \mathrm{H}\right] \mathrm{CpX}$ binding on pig urethra membranes (Supplemental Table 2). Additionally, CpX (10 $\mu \mathrm{M}$ maximum) was tested in numerous screening campaigns as well as in receptor/enzyme selectivity profiles (including $\mathrm{S} 1 \mathrm{P}$ receptors, $\mathrm{LPA}_{4-6}$, and $\mathrm{CB}_{1}$ ), but results never reached significant effect $(<50 \%$ at $10 \mu \mathrm{M})$ (Supplemental Table 3).

\section{Evidence for LPAR as Candidates}

$\left[{ }^{35} \mathbf{S}\right] G T P \gamma \mathbf{S}$ Binding Assay in Rat Brain Sections. In the panel of the first assays used to identify the CpX receptor and decipher its pathway, $\left[{ }^{35} \mathrm{~S}\right] \mathrm{GTP} \gamma \mathrm{S}$ binding in rat brain sections was studied after stimulation by $\mathrm{CpX}$ and $\mathrm{CpY}$ (1 $\mu \mathrm{M})$. Representative images of sections are shown in Fig. 2. As compared with control sections, CpX, and more intensely, $\mathrm{CpY}$, clearly enhanced the $\left[{ }^{35} \mathrm{~S}\right] \mathrm{GTP} \gamma \mathrm{S}$ signal in very specific areas, particularly those rich in white matter such as the corpus callosum and the internal capsule.

$\boldsymbol{\beta}$-Arrestin2 Recruitment Assay. In parallel, because numerous GPCRs were known to internalize after agonist stimulation through an interaction with $\beta$-arrestin 2 , a screening model aimed at identifying GPCR responders to $\mathrm{CpX}$ exposure was developed . $\beta$-arrestin 2 recruitment was monitored in COS-7 cells expressing a small collection of recombinant human GPCR and GFP-tagged $\beta$-arrestin2 (list of GPCR, Supplemental Table 3). No recruitment was observed in control COS-7 cells exposed to $1 \mu \mathrm{M}$ of $\mathrm{CpX}$ as well as in almost all COS-7 expressing a GPCR. In contrast, a redistribution of the $\beta$-arrestin2 fluorescence was observed along a 10-20-minute exposure to $0.5 \mu \mathrm{M}$ of $\mathrm{CpX}$ in COS-7 cells expressing recombinant human $\mathrm{LPA}_{1}$ (Fig. 3). A similar
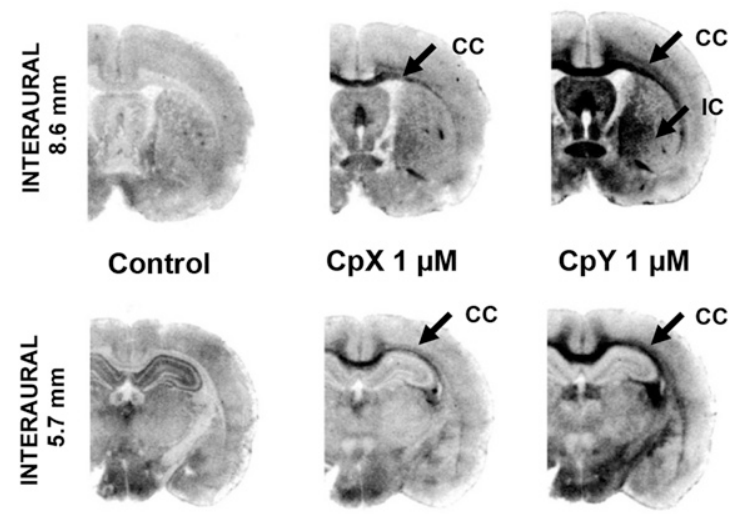

Fig. 2. Determination of $\left[{ }^{35} \mathrm{~S}\right]$ GTP $\gamma \mathrm{S}$-binding signal in control coronal sections of rat brain section or in sections stimulated by $1 \mu \mathrm{M}$ of $\mathrm{CpX}$ or CpY. Cc, corpus callosum; IC, internal capsule. 

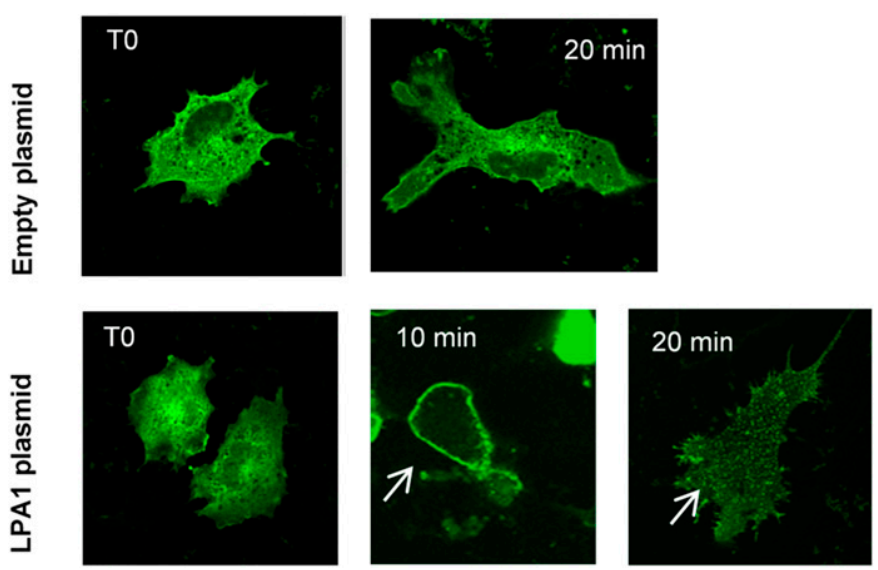

Fig. 3. Representative images of $\mathrm{CpX}$-induced redistribution of GFP$\beta$-arrestin2 in COS-7 cells expressing the LPA 1 receptor. COS-7 cells were transiently transfected with GFP- $\beta$-arrestin2, empty plasmid (top), or $\mathrm{LPA}_{1}$-plasmid (bottom), and redistribution was monitored by fluorescence microscopy. CpX was tested at 1 (controls) or $0.5 \mu \mathrm{M}\left(\mathrm{LPA}_{1}\right)$.

redistribution was observed in human $\mathrm{LPA}_{2}$-expressing COS7 cells.

Binding Confirmation for $\mathbf{L P A}_{1}$ and $\mathbf{L P A}_{2}$. For receptor characterization, $\mathrm{CpX}$ was radiolabeled with tritium (Fig. 1) and used to determine binding site constants in membranes prepared from urethra, the initial tissue found to be contracted by $\mathrm{CpX}$. Because the receptor was unknown, unlabeled $\mathrm{CpX}$ was used to define nonspecific binding after having confirmed the dynamic reversibility of the binding in association-dissociation studies. By using $10 \mathrm{nM}\left[{ }^{3} \mathrm{H}\right] \mathrm{CpX}$, a specific binding signal was observed in urethra membranes ( $\sim 80 \%, \sim 80 \mu \mathrm{g}$ of protein per point) from different species, but the pig urethra membrane preparation was selected for extended studies given the easier access to tissue and larger membrane production capacity. In pig urethra, $\mathrm{CpX}$ displayed a nanomolar affinity $\left(\mathrm{K}_{\mathrm{D}}=21 \pm 5.4 \mathrm{nM}, n=4\right)$ and maximal binding capacity at $1143 \pm 605 \mathrm{fmol} / \mathrm{mg}$ of protein (Fig. $4 \mathrm{~A}$ ). A similar affinity was obtained in human urethra smooth muscle cell membranes $\left(\mathrm{K}_{\mathrm{D}}=17 \pm 0.9 \mathrm{nM}, n=3\right)$, with a very similar saturation curve shape (Fig. 4B). To confirm the affinity of $\mathrm{CpX}$ for LPAR, membranes from $\mathrm{CHO}$ cells expressing recombinant $\mathrm{LPA}_{1}$ or $\mathrm{LPA}_{2}$ and two sphingosine1-phosphate receptors $\left(\mathrm{S}_{1} \mathrm{P}_{3}\right.$ and $\left.\mathrm{S}_{1} \mathrm{P}_{4}\right)$ were investigated. Using $40 \mathrm{nM}\left[{ }^{3} \mathrm{H}\right] \mathrm{CpX}$, a concentration slightly higher than the $K_{D}$ level obtained in urethra, no significant specific binding was found in our conditions in membranes (100-200 $\mu \mathrm{g}$ per point) prepared from control CHO cells $(<10 \%)$ or cells expressing either $\mathrm{S}_{1} \mathrm{P}_{3}(<10 \%)$ or $\mathrm{S}_{1} \mathrm{P}_{4}(<10 \%)$. In contrast, a high specific binding was observed in $\mathrm{LPA}_{1}(>80 \%)$ and $\mathrm{LPA}_{2}(>80 \%)$ membranes, and a saturation study (Fig. 4B) evidenced a nanomolar affinity constant for $\mathrm{hLPA}_{1}\left(\mathrm{~K}_{\mathrm{D}}=60 \pm\right.$ $10 \mathrm{nM}, n=3)$ and $\mathrm{hLPA}_{2}\left(\mathrm{~K}_{\mathrm{D}}=68 \pm 5.9 \mathrm{nM}, n=3\right)$. Issues in our laboratory to express sufficient $\mathrm{LPA}_{3}$ prevented the determination of $\mathrm{CpX}$ affinities on this receptor subtype. Alternatively, the ability of $\mathrm{CpX}, \mathrm{CpY}$, and $\mathrm{KI} 16425$ to displace $\left[{ }^{3} \mathrm{H}\right] \mathrm{CpX}$ binding in pig urethra membrane preparations was tested, showing pKi values of 7.8, 8.5, and 7.6, respectively (Table 1 ). No displacement $(<20 \%)$ was observed with the selective $\mathrm{LPA}_{3}$ antagonist (Cpd 701/Cpd 705, published $>13$ - to $>40$-fold selective, respectively, vs. $\mathrm{LPA}_{1-2}$ ) tested at $30 \mu \mathrm{M}$. KI16425 affinity for hLPA $(\mathrm{pKi}=7.5)$, but not that for hLPA $(\mathrm{pKi}=6.1)$, perfectly matched its affinity for the pig urethra sites. In recombinant cell membranes, KI16425 displayed a $\sim 20$-fold higher affinity for $\mathrm{LPA}_{1}$ versus $\mathrm{LPA}_{2}$ (Table 1), as previously described (Ohta et al., 2003). A slightly lower affinity for $\mathrm{LPA}_{2}$ was observed for $\mathrm{CpY}$.

\section{Functional Characterization}

Calcium Mobilization in $\mathbf{h L P A}_{1-3}$-Expressing Cells. The calcium responses in $\mathrm{hLPA}_{1-3}$-expressing cells were operated by Eurofins Pharma Discovery/Cerep in well validated experimental conditions that guaranteed the absence of response in native host cells. Accordingly, $\mathrm{CpX}$ and $\mathrm{CpY}$ had no effect in host cells $(<10 \%)$ but induced a dose-dependent calcium response in human receptor transfected cells, with an apparent range order of potency as follows: $\mathrm{hLPA}_{3}>\mathrm{hLPA}_{2}>\mathrm{hLPA}$ (Fig. 5). However, because the cell line and construct in Eurofins/Cerep $\mathrm{LPA}_{1}$ model were different from $\mathrm{LPA}_{2-3}$ models, the range of
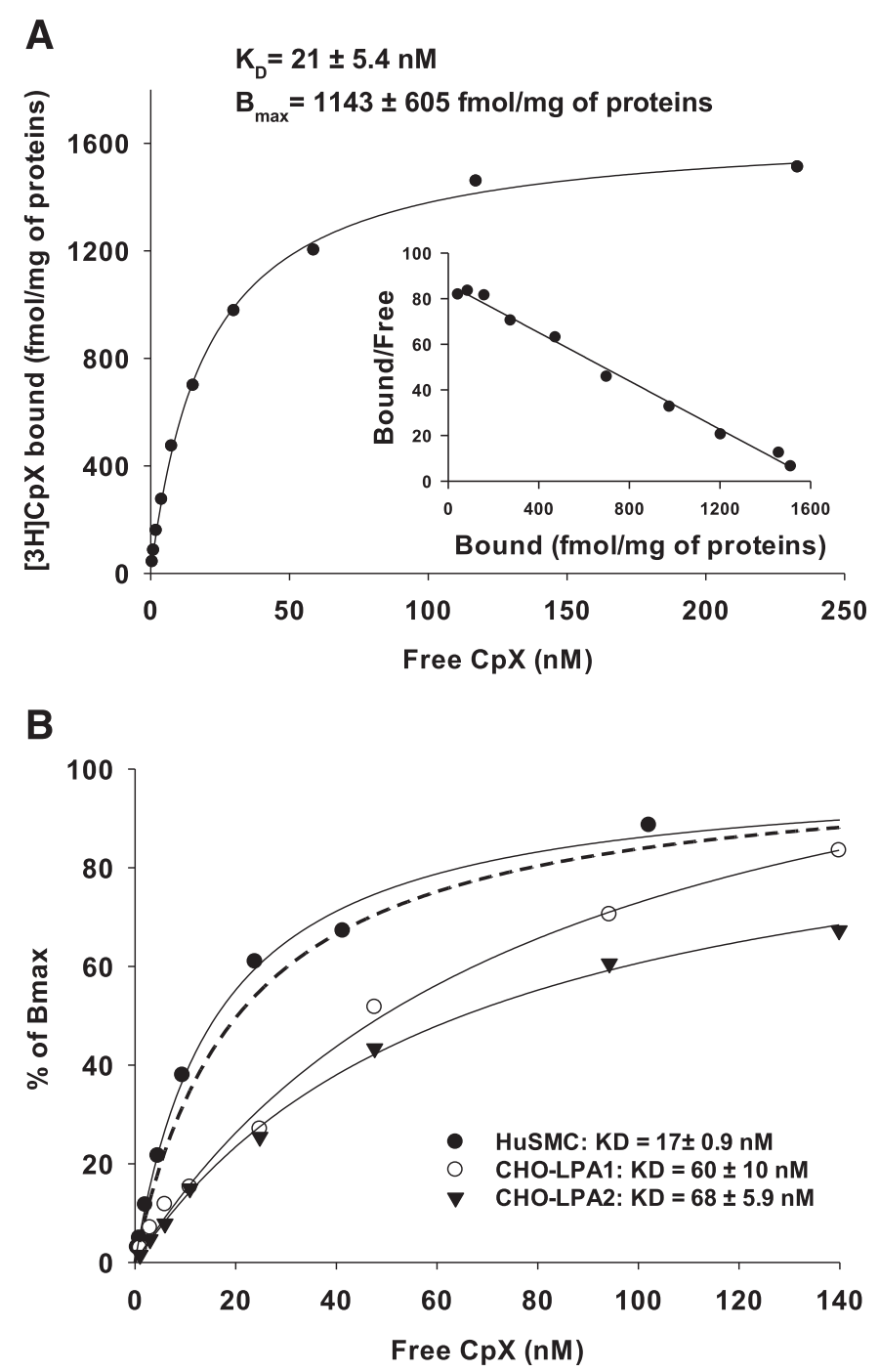

Fig. 4. Saturation curves of $\left.{ }^{3} \mathrm{H}\right] \mathrm{CpX}$ in membrane homogenates of pig urethra (A), human urethra smooth muscle cells (HuSMC), or CHO cells expressing recombinant $\mathrm{LPA}_{1}$ and $\mathrm{LPA}_{2}(\mathrm{~B})$. Curves are representative of at least three independent experiments, from which affinity values were determined by nonlinear regression using iterative fitting procedures. Dotted line in (B) represents the saturation obtained with pig urethra membranes given in (A). Figure values are means of triplicates. $K_{D}$ and Bmax data are means \pm S.D. 
TABLE 1

Binding affinity $(\mathrm{pKi})$ and contractile potency $\left(\mathrm{pEC}_{50}\right)$ values.

Ki values were calculated from the capacity of compounds to displace $\left[{ }^{3} \mathrm{H}\right] \mathrm{CpX}$ binding to indicated membranes (IC 50 ) by using Cheng Prussoff formula $(n \geq 2)$. Contractile potency was measured in rabbit urethra strips and $\mathrm{EC}_{50}$ determined by nonlinear sigmoid regression $(n=6)$. Data are expressed as $-\log 10\left(\mathrm{Ki}\right.$ or $\left.\mathrm{EC}_{50}\right) \pm$ S.D.

\begin{tabular}{lcccc}
\hline & \multicolumn{3}{c}{ Binding Affinities (pKi) } & \multicolumn{2}{c}{ Tissue Contraction (pEC ${ }_{50}$ ) } \\
\cline { 2 - 4 } & hLPA1 & hLPA2 & Pig Urethra & Rabbit Urethra \\
\hline KI16425 & $7.5(7.3-7.7)$ & $6.1(5.9-6.4)$ & $7.6(7.6-7.6)$ & \\
CpX & $7.3 \pm 0.2$ & $7.1 \pm 0.2$ & $7.8 \pm 0.2$ & $8.0 \pm 0.2$ \\
CpY & $8.3 \pm 0.2$ & $7.7 \pm 0.3$ & $8.5 \pm 0.2$ & $8.2 \pm 0.2$ \\
\hline
\end{tabular}

potency of our agonists for $\mathrm{hLPA}_{1-3}$ is likely biased, as underlined by the marked difference of responses to the nonspecific native ligand, Oleoyl-LPA, in $\mathrm{hLPA}_{1}\left(\mathrm{pEC}_{50}=\right.$ 6.8) as compared with hLPA $\left(\mathrm{pEC}_{50}=8.4\right)$ and $\mathrm{hLPA}_{3}\left(\mathrm{pEC}_{50}\right.$ $=8.7$ ) expressing cells. When compared head to head with Oleoyl-LPA in each model, CpX appeared 7.5-fold less potent in $\mathrm{hLPA}_{1}\left(\mathrm{pEC}_{50}=5.9\right)$ and $\sim 30$-fold less potent in both $\mathrm{hLPA}_{2}$ $\left(\mathrm{pEC}_{50}=6.9\right)$ and $\mathrm{hLPA}_{3}\left(\mathrm{pEC}_{50}=7.2\right)$ expressing cells. CpY was $\sim$ threefold more potent than $\mathrm{CpX}$, displaying only 2.7 -fold lower potency in $\mathrm{hLPA}_{1}\left(\mathrm{pEC}_{50}=6.3\right)$ and 9-fold lower potency in both $\mathrm{hLPA}_{2}\left(\mathrm{pEC}_{50}=7.5\right)$ and $\mathrm{hLPA}_{3}\left(\mathrm{pEC}_{50}=7.7\right)$ expressing cells, compared with Oleoyl-LPA.

Contraction of Smooth Muscles. The contractile features of $\mathrm{CpX}$ were investigated in rabbit urethra strips. All strips were precontracted by $100 \mu \mathrm{M}$ phenylephrine to qualify tissue contractility. CpX contracted urethra strips in an incremental manner to reach a plateau $(\sim 75 \%-85 \%$ of the effect of $100 \mu \mathrm{M}$ phenylephrine) in the lower micromolars range (Fig. 6). In these conditions, $\mathrm{CpX}$ displayed a $\mathrm{pEC}_{50}$ at $8.0 \pm 0.2(n=6)$. A Schild Plot analysis was conducted to characterize KI16425 antagonism. As depicted in Fig. 6A, increasing KI16425 concentrations shifted the contracting responses of $\mathrm{CpX}$ to the right, allowing the determination of a $\mathrm{pK}_{\mathrm{B}}$ of 7.35 (slope not different from 1). The contracting response of $\mathrm{CpX}$ was also explored in urethra strips from other species (Fig. 6B), giving a similar contraction profile and efficacy values for pig $\left(\mathrm{pEC}_{50}=7.9 \pm 0.1, n=8\right), \operatorname{dog}\left(\mathrm{pEC}_{50}=\right.$ $8.1 \pm 0.1, n=7)$, rat $\left(\mathrm{pEC}_{50}=8.4 \pm 0.3, n=7\right)$, and human prostatic adenoma $\left(\mathrm{pEC}_{50}=7.8 \pm 0.2, n=3\right)$. Accordingly, by testing a single concentration of KI16425 on CpX-induced contraction, the level of KI16425 potency was estimated in rat urethra $\left(\mathrm{pA}_{2}=7.5\right)$ and human prostatic adenoma $\left(\mathrm{pA}_{2}=7.34\right)$. Additionally, $\mathrm{LPA}_{1}$ was mostly expressed in the human prostate (mRNA abundance of hLPA $\mathrm{A}_{1-2-3}: 72 \% / 10 \% / 18 \%$ ). Close analogs of $\mathrm{CpX}\left(\mathrm{CpZ}_{1}\right.$ to $\left.\mathrm{CpZ}_{3}\right)$ with variable binding affinity were also evaluated (Fig. 6C), and a strong correlation was obtained $\left(R^{2}=0.97\right)$ between their abilities to displace $\left[{ }^{3} \mathrm{H}\right] \mathrm{CpX}$ binding in pig urethra membrane and to contract rabbit urethra (Fig. 7). All analogs behaved as weaker contractant as compared with $100 \mu \mathrm{M}$ phenylephrine response, reaching in this experiment, respectively, $82 \% \pm$ $31 \%$ at $0.3 \mu \mathrm{M} \mathrm{CpX}, 52 \% \pm 5 \%$ at $0.3 \mu \mathrm{M} \mathrm{CpY}, 83 \% \pm$ $16 \%$ at $30 \mu \mathrm{M} \mathrm{CpZ}, 78 \% \pm 19 \%$ at $100 \mu \mathrm{M} \mathrm{CpZ}$, and $64 \% \pm 13 \%$ at $300 \mu \mathrm{M} \mathrm{CpZ}$ of maximal phenylephrine contraction. Another analog without amine derivative $\left(\mathrm{CpZ}_{4}\right)$ was considered inactive.

In Vivo Increase in Intraurethral Pressure. Intraurethral pressure (IUP) was measured in anesthetized female rat. The anesthesia procedure was qualified by the absence of significant effects on basal urethral pressure along the duration of the experiment ( 2 hours). Under these conditions, the baseline IUP measured was $\sim 12 \mathrm{cmH}_{2} \mathrm{O}$ (Supplemental Table 4). Successive intravenous perfusion of $\mathrm{CpX}$ dosedependently increased IUP with a first significant dose established at $1 \mu \mathrm{g} / \mathrm{kg}$ and a maximal increase representing $+88 \%$ from baseline reached at $30 \mu \mathrm{g} / \mathrm{kg}$ (Fig. 8; Supplemental Table 4). CpY was more potent and increased IUP significantly from $0.3 \mu \mathrm{g} / \mathrm{kg}$ with a maximal increase of $+102 \%$ at $3 \mu \mathrm{g} / \mathrm{kg}$. As a comparator, the $\alpha 1$-adrenoceptor agonist phenylephrine was markedly less potent with a first significant dose at $30 \mu \mathrm{g} / \mathrm{kg}$ and a maximal increase of $+74 \%$ at $100 \mu \mathrm{g} / \mathrm{kg}$. The estimated doses increasing by $50 \%$ urethral pressure $\left(\mathrm{DE}_{50 \%}\right)$ were $0.4 \mu \mathrm{g} / \mathrm{kg}$ for $\mathrm{CpY}, 1.3 \mu \mathrm{g} / \mathrm{kg}$ for $\mathrm{CpX}$, and $35 \mu \mathrm{g} / \mathrm{kg}$ for phenylephrine. Compared with phenylephrine, which significantly increased mean arterial pressure (MAP) from $1 \mu \mathrm{g} / \mathrm{kg}, \mathrm{CpX}$ was neutral on blood pressure up to $30 \mu \mathrm{g} / \mathrm{kg}$, where a modest reduction in MAP was observed (Supplemental Table 4). All compounds reduced heart rate at the highest doses. In addition, the pharmacokinetics of $\mathrm{CpY}$ were investigated at $1 \mathrm{mg} / \mathrm{kg}$ i.v. in rats. $\mathrm{CpY}$ was quantified at $0.5 \mu \mathrm{M}$ postinjection and above the limit of detection for 6 hours in plasma with a urethra/plasma area under the curve ratio of 6.1. The limit of detection established at $32 \mathrm{nM}$ was above the affinity $(5 \mathrm{nM})$ of $\mathrm{CpY}$ for $\mathrm{LPA}_{1}$.

Blockade of Preadipocyte Differentiation. To more extensively confirm the LPAR agonistic activity in a human biologic system unrelated to muscle contraction, human preadipocytes were extracted from liposuction samples and allowed to differentiate into mature adipocytes as previously described (Halvorsen et al., 2001). Full maturation was monitored by the expression of the late differentiation markers perilipin and adiponectin (control without $\mathrm{CpX}$ in Fig. 9). $\mathrm{CpX}$ added at the beginning of differentiation decreased the expression of both markers in a concentrationdependent manner $(1 \mathrm{nM}$ to $10 \mu \mathrm{M})$, with an estimated $\mathrm{pIC}_{50}=$ 8. A similar effect was obtained with $\mathrm{CpY}$ (Supplemental Fig. 1). $\mathrm{CpX}$ inhibitory response was antagonized by increasing concentrations of $\mathrm{KI} 16425$ (estimated $\mathrm{pA}_{2}$ at 7.3 and 7.2, respectively), with a nearly total reversal at $10 \mu \mathrm{M}$. A trend toward an increase in adiponectin, but less in perilipin expression, was observed in the presence of KI16425. As complementary information, $\mathrm{LPA}_{1}$ was mostly expressed in fat cells as compared with $\mathrm{LPA}_{2}$ and with $\mathrm{LPA}_{3}$ (mRNA abundance of $\mathrm{LPA}_{1-2-3}: 98.2 \% / 1.8 \% /<0.1 \%$ in human preadipocytes and $98.8 \% / 0.9 \% / 0.3 \%$ in human adipocytes).

Molecular Modeling. To better understand and compare the molecular interaction mode of the compounds, homology models of $\mathrm{LPA}_{1-3}$ have been built, and $\mathrm{CpX}, \mathrm{CpY}$, and the natural agonist (18:1-LPA) have been docked onto the "classical" active cleft (meaning the same pocket as retinal in rhodopsin reference structure). CNR1_HUMAN was used as a template (pdb id: $5 \times 18$ ) because it 1 ) belongs to the same 


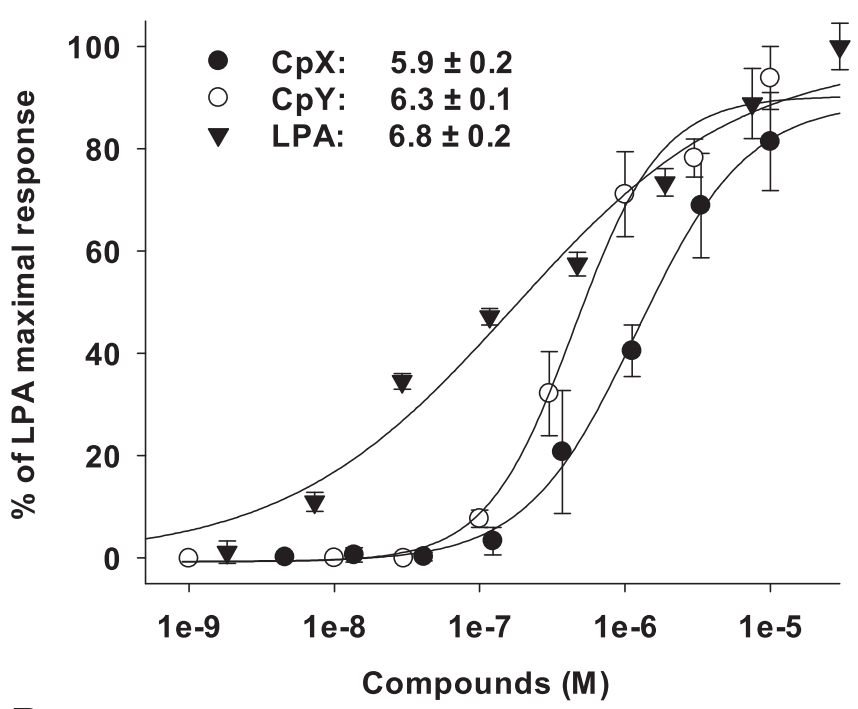

B
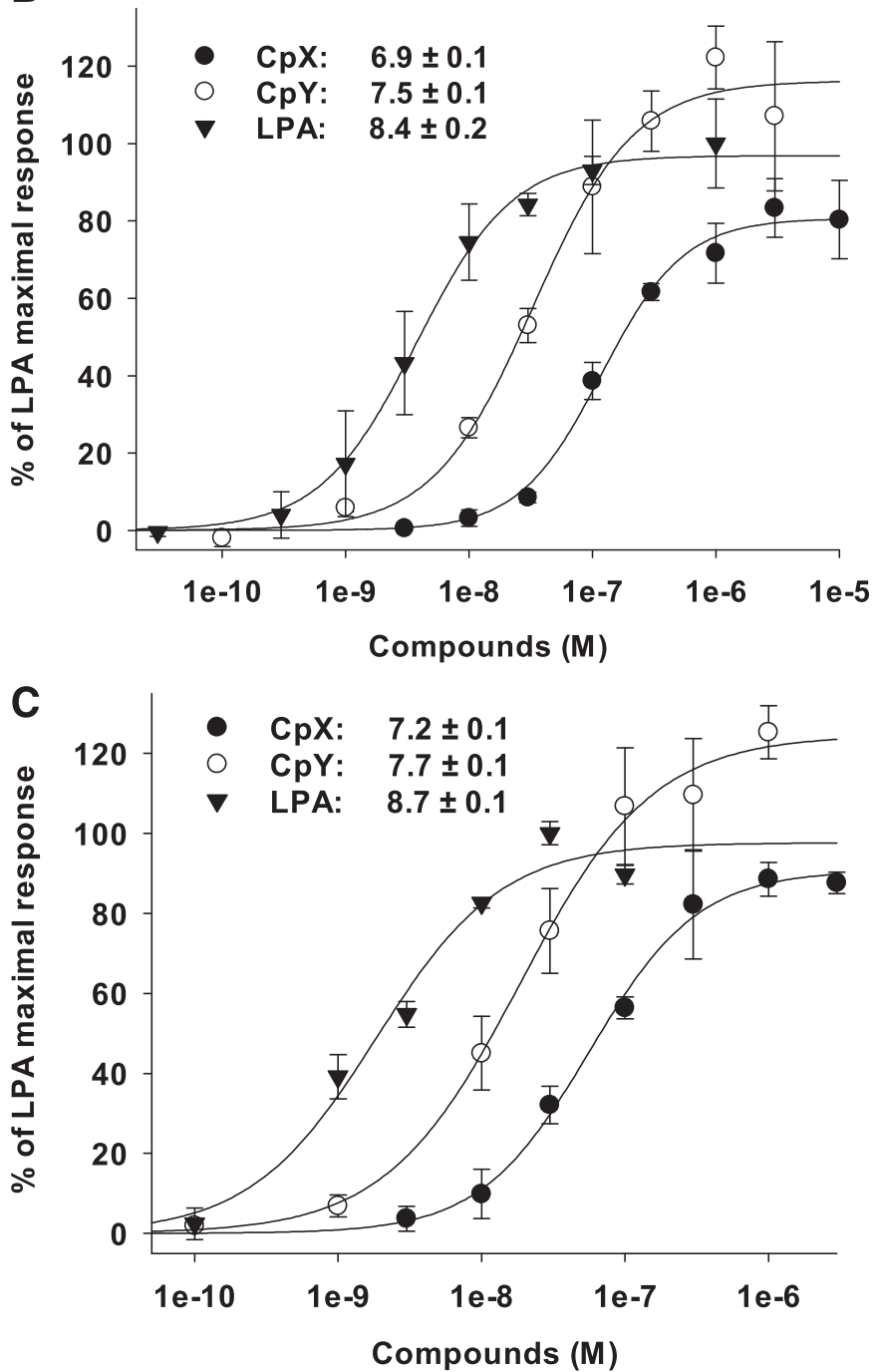

Fig. 5. Calcium mobilization response of $\mathrm{CpX}, \mathrm{CpY}$, and Oleoyl-LPA in Chem-1 cells expressing hLPA 1 (A) and CHO-K1 cells expressing hLPA (B) or hLPA $\mathrm{CH}_{3}$ (C). Data are expressed as percent of LPA maximal response and expressed as means \pm S.D. $(n=3)$. Respective agonist potency is expressed as $\mathrm{pEC}_{50} \pm$ S.D. $(n=3)$. branch of the GPCR phylogenetic tree (Fredriksson et al., 2003), 2) has the same length and secondary structure (no disulfide bond located in the beginning of TM3 but one in the loop) of the very important second external loop that covers the active site, and 3 ) is in an activated conformation able to dock agonist compounds. By following the specific strategy (especially for TM5) described in the Materials and Methods section, about 200 models were generated for each receptor by varying sidechain conformations and using the simulated annealing capacity of the homology procedure to sample active cleft shape and properties (Nilges and Brünger, 1991). After docking and analysis of clustering on $\mathrm{LPA}_{1}$, the best poses showed very similar interactions for $\mathrm{CpX}$ and $\mathrm{CpY}$ : a pi-cation interaction between the amine and W5.43 (Trp210), an ion bridge with D3.33 (Asp129), a hydrogen bond between the ethanol moiety and D3.33 (Asp129) and Q3.29 (Gln125) or Y2.57 (Tyr102) for some clusters, and the benzofuran into the hydrophobic pocket made by W5.43 (Trp210), L6.55 (Leu278), L7.39 (Leu297), L3.36 (Leu132), A7.42 (Ala300), W6.48 (Trp271) (Fig. 10; Table 2). The same interaction pattern and glide score repartition has been obtained for best docking poses in $\mathrm{LPA}_{2}$ and $\mathrm{LPA}_{3}$ (Fig. 10; Table 2). When 18:1-LPA was docked in $\mathrm{LPA}_{1}$, its hydrophobic tail was shown to fill the same area occupied by our compounds. However, its polar phosphate group made an ionic bridge with K7.36 (Lys294), and its ester moiety made hydrogen bonds with Y2.57 (Tyr102) and Q3.29 (Gln125), both residues located closer to the edge of the site (Fig. 10). Additionally, this analysis applied to $\mathrm{CpX}$ derivatives likely provides an interesting hypothesis for the structure-activity relationship (shown in Fig. 7), namely, the importance of 1) the pi-cation interaction (lack of amine in CpZ4), 2) the hydrophobic benzofuran core (hydrophilic bulge in CpZ3) and of the exact orientation of ethanolamine versus benzofuran (CpZ2 and CpZ1), and 3) the chirality, with the $\mathrm{CpX}$ enantiomer being significantly less potent $\left(\mathrm{pIC}_{50}=6.7\right)$.

\section{Discussion}

Serendipity is sometimes at the origin of breakthrough discoveries. As an example, the present study relates the identification of the target of receptor-orphan chemical structures, initially characterized as potent urethra contracting agents (Philippo et al., 1998a,b). These molecules, originating from adrenergic-like agonist series, contracted rabbit urethra but unexpectedly could not be antagonized by the $\alpha_{1}$-adrenoceptor antagonist prazosin. To identify the elusive receptors, numerous reference molecules were screened (on urethra contraction and $\left[{ }^{3} \mathrm{H}\right] \mathrm{CpX}$ binding) and $\mathrm{CpX}$ profiled on available panels of receptors, but all efforts failed, thus reinforcing the originality of the quest. After ultimate but unsuccessful attempts to purify the receptor, the clues for LPAR as candidates arose fortuitously. The first hints came from $\left[{ }^{35} \mathrm{~S}\right]$ GTP $\gamma \mathrm{S}$ activation experiments performed in rat brain slices, which revealed specific signals in white matter tracts known as areas rich in myelin (Rozenblum et al., 2014). Among a few possible receptors, $\mathrm{LPA}_{1}$ was suspected because an enrichment was observed in myelin-rich areas (Handford et al., 2001). Separately, a $\beta$-arrestin 2 recruitment screening campaign applied to a collection of GPCR overexpressing cells pinpointed two hits responding to $\mathrm{CpX}$ : $\mathrm{hLPA}_{1}$ and $\mathrm{hLPA}_{2}$. With this hypothesis in mind, we confirmed that $\left[{ }^{3} \mathrm{H}\right] \mathrm{CpX}$ was 

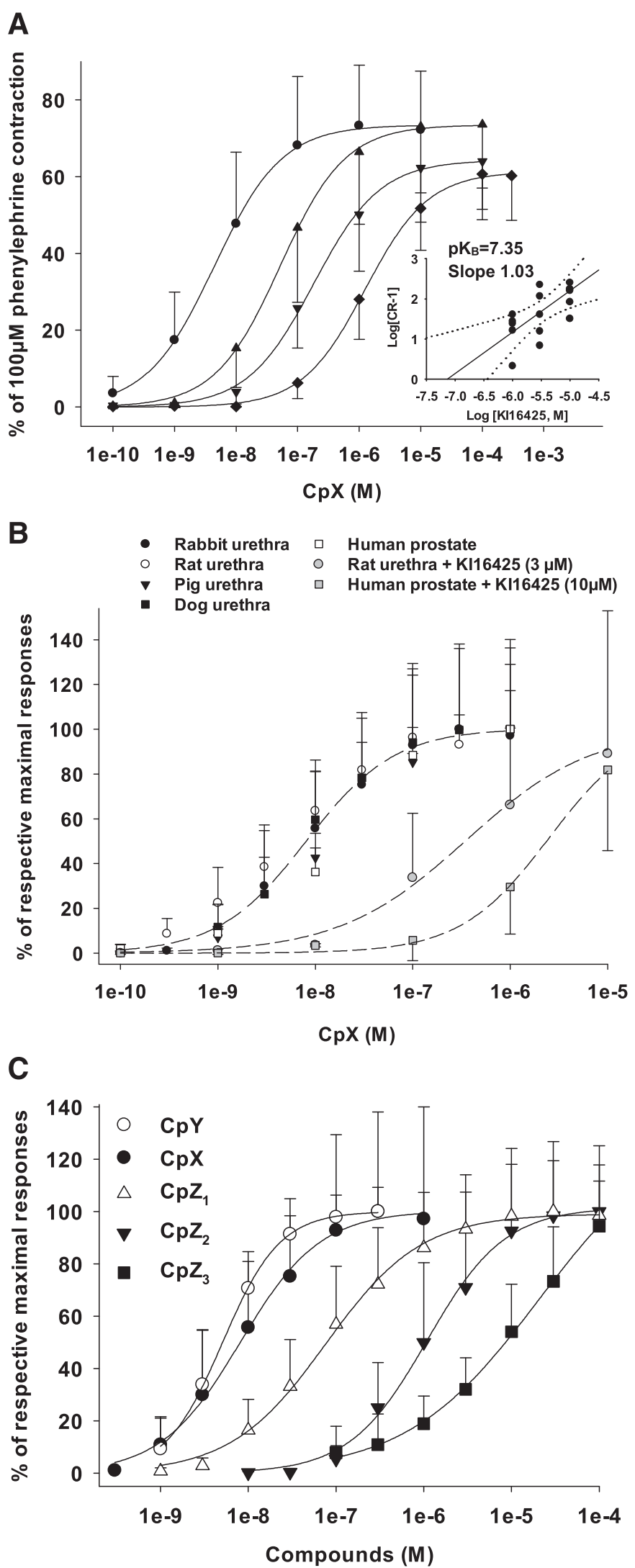

Fig. 6. Effect of KI16425 on CpX-mediated contraction of rabbit urethra strips (A): controls (-) and in the presence of $1 \mu \mathrm{M}$ KII6425 (A), $3 \mu \mathrm{M}$ $\mathrm{KI} 16425(\boldsymbol{\nabla})$, or $10 \mu \mathrm{M} \mathrm{KI} 16425(\diamond) . \mathrm{CpX} \mathrm{pEC}_{50}$ for control group was $8.0 \pm$ 0.2 , and $\mathrm{pK}_{\mathrm{B}}$ was measured at 7.35 for KI16425 (included Schild Plot analysis, slope not statistically different from 1,95\% confidence a strong binder of $\mathrm{LPA}_{1}$ and $\mathrm{LPA}_{2}$. A similar two-digit nanomolar affinity site was detected in membranes of $\mathrm{hLPA}_{1}$ expressing cells and of pig urethra. Binding displacement results obtained with specific antagonists demonstrated the predominant interaction with $\mathrm{LPA}_{1}$ in this tissue. The conclusion is supported by the selectivity profile of KI16425 $\left(\mathrm{LPA}_{1} \geq \mathrm{LPA}_{3}>>\mathrm{LPA}_{2}\right)$, the perfect matching of the affinities of $\mathrm{KI} 16425$ for urethra and $\mathrm{hLPA}_{1}$, and the absence of displacement with Ceretek $\mathrm{LPA}_{3}$ antagonists. From a functional perspective, the cellular calcium mobilization responses induced by $\mathrm{CpX}$ clearly showed an activation of $\mathrm{LPA}_{1-2}$ but also $\mathrm{LPA}_{3}$, with a $1-\log \left(\mathrm{LPA}_{1}\right)$ to $1.5-\log \left(\mathrm{LPA}_{2-3}\right)$ lower potency as compared with Oleoyl-LPA (0.4-1-log for CpY), thus presaging significant tissue contraction responses. Indeed, not only did CpX potently contract rabbit urethra, but it also induced very significant contractions in dog, rat, and pig urethras as well as in human prostate. In agreement with its LPA $_{1}$-binding affinity, KI16425 potently antagonized CpXinduced rabbit urethra contraction but also rat urethra and human prostatic adenoma contractions. Importantly, the implication of the $\mathrm{LPA}_{1}$ pathway was confirmed by the strong correlation between binding affinity and contracting potency obtained with benzofuran derivatives displaying a range of various affinities. To our knowledge, LPA-induced contractile responses have only been tested in rat urethra strips (Saga et al., 2014; Sakamoto et al., 2018), in which a pivotal role of LPA $_{1}$ was pointed out only recently in Sakamoto's study. Nevertheless, LPA was only active at high concentrations $(\geq 1$ $\mu \mathrm{M})$, suggesting a fast degradation. Following these observations, $\mathrm{CpX}$ clearly behaves as a more potent $\mathrm{LPA}_{1}$ agonist in isolated strips than LPA. Our data also extend the central role of $\mathrm{LPA}_{1}$ in urethra and prostate contractions to humans and other species. Another notable finding is that $\mathrm{CpX}$ and, even more so, CpY potently increased IUP in vivo in anesthetized female rats at low concentrations, which ranks it more efficacious than phenylephrine taken as a reference. As such, $\mathrm{CpY}$, with an absolute IUP increase of $16 \mathrm{cmH}_{2} \mathrm{O}$ at $3 \mu \mathrm{g} / \mathrm{kg}$, appeared to be several orders of magnitude more potent in vivo than LPA, for which $300 \mu \mathrm{g} / \mathrm{kg}$ was shown to increase IUP by $5 \mathrm{~mm} \mathrm{Hg}$ (which corresponds to $6.8 \mathrm{cmH}_{2} \mathrm{O}$ ) in a similar rat model (Terakado et al., 2016). This difference in efficacy likely results from a higher and longer $\mathrm{LPA}_{1}$ activation because of a better plasma stability of $\mathrm{CpY}$ (hour-lasting half-life) compared with the minute-lasting half-life of LPA (Salous et al., 2013). Unlike phenylephrine, which increased MAP, only a reduction of MAP was observed at the highest doses of $\mathrm{CpX}$, thus supporting a lower incidence on cardiovascular function at doses increasing urethral pressure. Interestingly, LPA was shown to induce a transient MAP elevation by interacting with $\mathrm{LPA}_{4}$ and $\mathrm{LPA}_{6}$ (Kano et al., 2019), which likely explains the different hemodynamic profile of our selective $\mathrm{LPA}_{1-3}$ agonists. Like phenylephrine, our compounds decreased heart rate but not through a baroreflexmediated mechanism, as blood pressure remained mainly unchanged. The mechanism responsible for this reduction in

interval( $\cdots)$. Data are transformed in percent of $100 \mu \mathrm{M}$ phenylephrine response $(n=7)$. (B) Comparative responses of tissues from different species to $\mathrm{CpX}(n=3-7)$ and (C) comparative response of rabbit urethra to a small series of benzofuran ethanolamine derivatives $(n=4-8)$. Data are expressed in percent of respective maximal responses and means \pm S.D. 


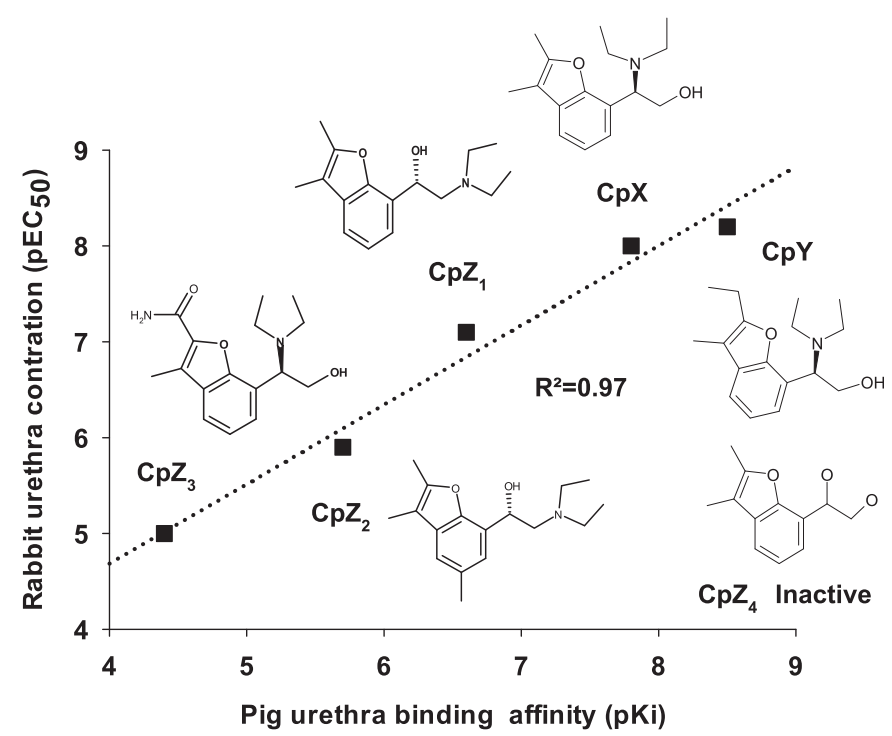

Fig. 7. Correlation between pig urethra membrane affinity (pKi) and rabbit urethra contraction $\left(\mathrm{pEC}_{50}\right)$ for a small series of benzofuran ethanolamine derivatives. $\mathrm{CpZ}_{1-4}$ was selected to represent a large range of binding affinities.

heart rate is not yet identified. For the first time, a marked increase in urethral tone was obtained by directly targeting $\mathrm{LPA}_{1}$ with a nonlipid agent. Accordingly, a decrease in urethral tone was demonstrated after injection of the specific ATX inhibitor ONO-8430506 (Saga et al., 2014) or after treatment with the new specific $\mathrm{LPA}_{1}$ antagonist ASP6462 (Sakamoto et al., 2018), suggesting an endogenous LPA/LPA 1 tone. Interestingly, ASP6462 decreased urethral pressure during urine voiding and improved L-NAME-induced voiding dysfunction, which differs from tamsulosin, underlining important differences between $\mathrm{LPA}_{1}$ and $\alpha 1$-adrenergic regulations (Sakamoto et al., 2019). Although of significant concern for women, no drug therapy has been approved by health authorities so far, and very few drugs are registered for pure stress incontinence. A trial has recently been conducted with the antidepressant serotonin/norepinephrine reuptake inhibitor imipramine but ended up with inconclusive results (Kornholt et al., 2019). Offlabel use of several agents such as $\alpha_{1}$-adrenergic agonists are reported with variable efficacy and side effects that limit their use (Malallah and Al-Shaiji, 2015). In that context, our new potent LPAR agonists should facilitate more dedicated investigations to clarify the therapeutic potential of LPA/LPAR pathway in stress incontinence.

Moreover, we further completed the characterization of our agonists in human preadipocyte differentiation process. Indeed, through paracrine and autocrine signaling, the ATXLPA axis, acting most likely via $\mathrm{LPA}_{1}$, was shown to switch the balance from differentiation to proliferation of preadipocytes, thus altering fat storage (Simon et al., 2005; Dusaulcy et al., 2011). Accordingly, our agonists potently inhibited the maturation process, as shown by the reduced expression of the two late markers, perilipin and adiponectin. Conversely, KI16425 restored the inhibition of the maturation process. The presence of endogenous production of LPA likely explains why KI16425 alone slightly increased differentiation level. These new findings confirm the tight control of adipocyte maturation by $\mathrm{LPA}_{1}$ and open new avenues for investigations in obesity, aiming at clarifying the global benefit and risk (fat storage reduction/inflammation, insulin resistance) of activating the ATX-LPA axis (D'Souza et al., 2018).

However, our studies have some limitations. First, we did not compare the effects of our compounds and LPA in tissue material assays head to head. We initially attempted to displace $\left[{ }^{3} \mathrm{H}\right] \mathrm{CpX}$ binding by LPA but failed because of a very rapid degradation, confirmed by using radiolabeled LPA. Similar labile behavior of LPA was observed in tissue contraction conditions. Second, even if we could compare our compounds to Oleoyl-LPA in calcium mobilization assays, we could not estimate their absolute selectivity patterns for $\mathrm{LPA}_{1-3}$. Indeed, difference in cell line, level of receptor expression, and nonphysiologic coupling likely introduced bias in compound responses, well exemplified by the lower responses to LPA in $\mathrm{LPA}_{1}$ than in $\mathrm{LPA}_{2-3}$-overexpressing cells.

The structure-activity relationship also indicates that moderate modifications of the structural backbone can finely tune their LPA $_{1}$ efficacy, hopefully opening room for selectivity improvement toward $\mathrm{LPA}_{2}$ and $\mathrm{LPA}_{3}$. Because these molecules have no aliphatic chain, their interaction with LPAR could not be anticipated considering the interaction mode of LPA with the amphipathic binding pocket of $\mathrm{LPA}_{1}$ (Chrencik et al., 2015). Additionally, classic LPAR ligands contain a large nonpolar region and chiral hydroxyl, ester, and carboxylic acid groups. In contrast, $\mathrm{CpX}$ and derivatives are basic molecules at physiologic $\mathrm{pH}(\mathrm{pKa} \geq 8.8)$ and are less lipophilic $(\log \mathrm{P} \leq$ 3.9). Interestingly, by using an optimized strategy for TM assignation applied to a GPCR modeling template close to $\mathrm{LPA}_{1-3}$ (CNR1) and suitable for agonist docking purpose, a high glide score and high-quality interaction pattern were obtained for $\mathrm{CpX}$ and $\mathrm{CpY}$ with $\mathrm{LPA}_{1}$. This specific interaction is notably characterized by a clear pi-cation interaction with a tryptophan residue, an ionic bridge with an acidic residue, and the embedding of the benzofuran in a specific hydrophobic pocket. Nevertheless, these docking results cannot explain the difference in $\mathrm{LPA}_{1}$ affinity and calcium response as well in urethral response profile measured between the very similar compounds $\mathrm{CpX}$ and $\mathrm{CpY}$. The same interaction pattern was

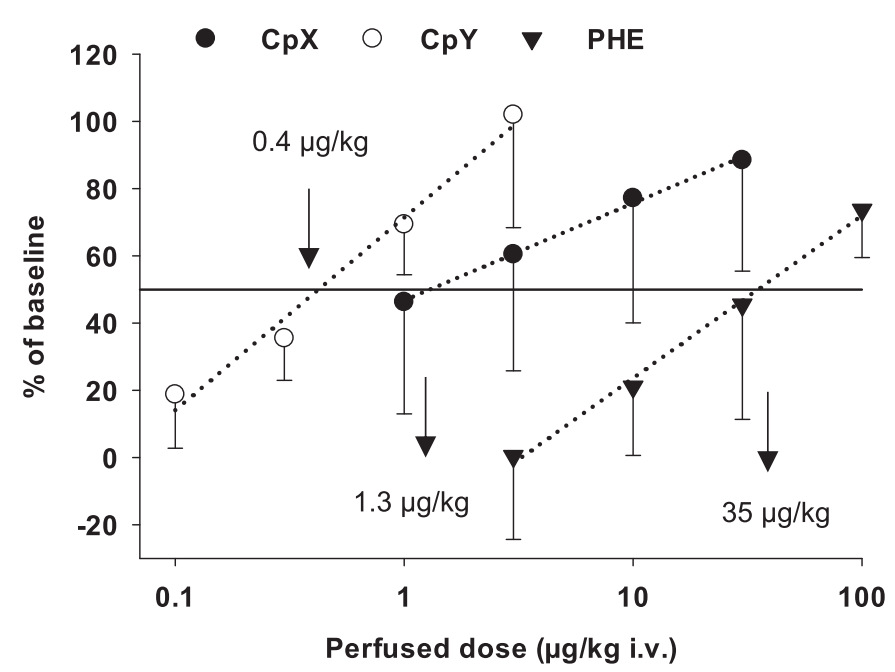

Fig. 8. Effect of agonists perfusion on IUP. Anesthetized female rats received successive increasing dose of $\mathrm{CpX}, \mathrm{CpY}$, or phenylephrine $(n=$ 3-6). IUP $\left(\mathrm{cmH}_{2} \mathrm{O}\right)$ was measured before (baseline) or after the end of each incremental perfusion (raw data given in Supplemental Table 4) and expressed as percent of respective baseline (means \pm S.D.). $\mathrm{DE}_{50 \%}$ were estimated from nonlinear regression by using iterative fitting procedures. 

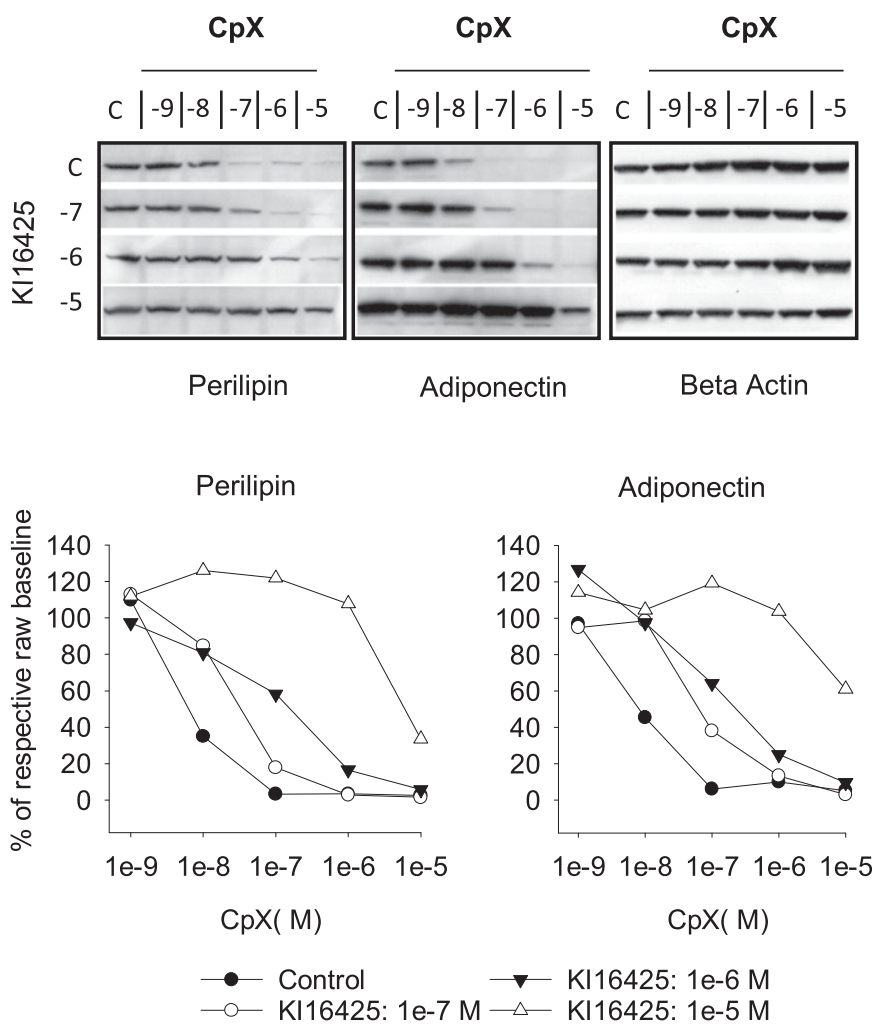

Fig. 9. Effect of $\mathrm{KI} 16425$ on $\mathrm{CpX}$ inhibition of human preadipocyte differentiation. Differentiation into mature adipocyte was confirmed by the expression of the two late markers perilipine and adiponectin separated by Western blot. $\beta$-actin was used as normalization protein. $\mathrm{CpX}$ alone or in the presence of KI16425 were added at the initiation of the differentiation process at indicated log [concentration]. This separation is representative of two independent experiments. Data were normalized by $\beta$-actin expression and represented as percent of respective raw control (bottom). C, control.

obtained with $\mathrm{LPA}_{2-3}$ in agreement with a very high level of residue identity. In contrast, LPA yielded a completely different pattern of polar-based interactions. Indeed, its polar head interacts with residues at the external edge of the site, far from $\mathrm{CpX} / \mathrm{CpY}$ ionic bridges, whereas the hydrophobic tail of LPA and the benzofuran moiety of $\mathrm{CpX} / \mathrm{CpY}$ stand in the same hydrophobic pocket. This analysis agrees with the docking of LPA into an inactivated $\mathrm{LPA}_{1}$ structure (pdb id: 4z34), published by Balogh et al. (2015).

Although the exact interactions of our compounds with $\mathrm{LPA}_{1-3}$ would need crystallography investigations, these modeling explorations support that structurally different ligands can activate $\mathrm{LPA}_{1-3}$, likely through the interaction with the identified hydrophobic pocket.

To conclude, these LPAR agonists are unique at this level of potency, selectivity, and especially stability compared with LPA and represent more appropriate tools for investigating the physiologic and pathologic roles of LPAR pathways.

\section{Acknowledgments}

We would like to acknowledge the numerous Sanofi R\&D heads of services, scientists (biologists and chemists), and especially Sonia Arbilla, Philippe Bovy, Itzchak Angel, Anne Marie Galzin, Denis Martin, Pascual Ferrara, Olivier Curet, Annick Coste, François LoPresti, Gilles Courtemanche, Pascal Shiltz, Mourad Kaghad, Anne Remaury, Stéfano Paléa, Philippe Lluel, Bruno Chevallier, Martine
A

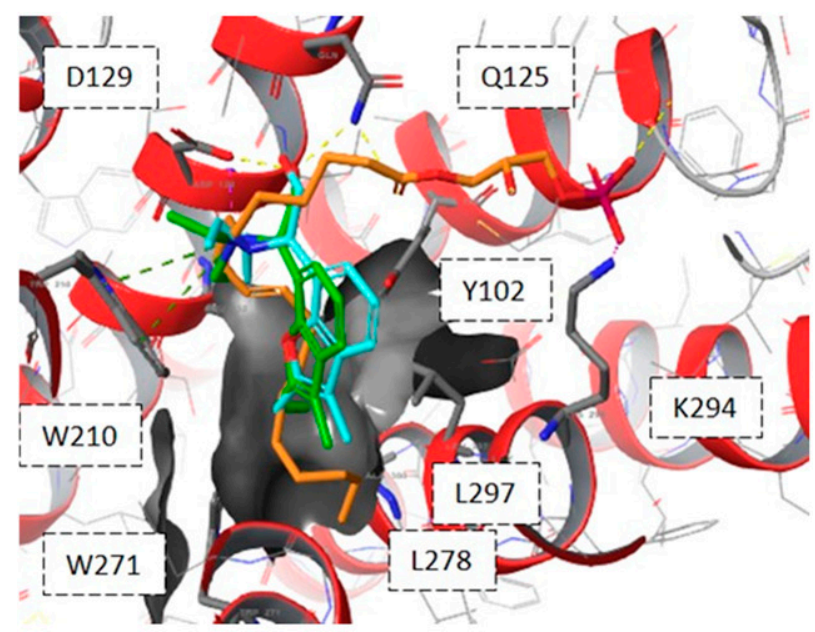

B

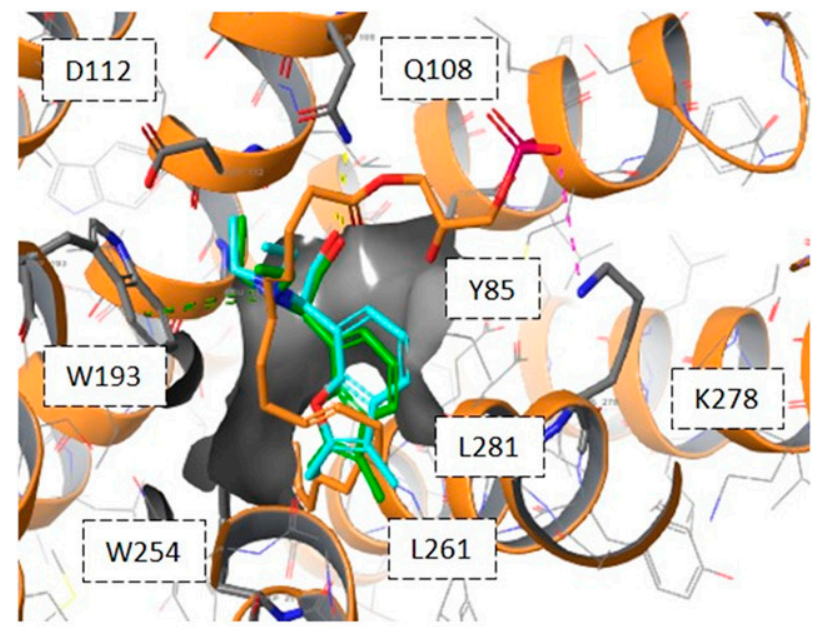

C

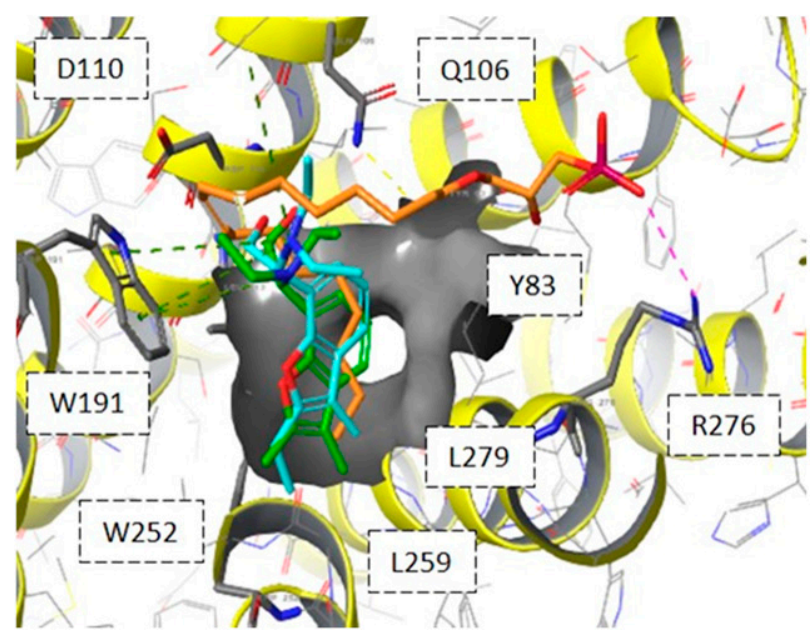

Fig. 10. Analysis of ligand binding pocket of $\mathrm{hLPA}_{1-3}$ residues. Superimposition of docking poses of $\mathrm{CpX}$ (blue), $\mathrm{CpY}$ (green), and 18:1-LPA (orange) on $\mathrm{LPA}_{1}(\mathrm{~A}), \mathrm{LPA}_{2}(\mathrm{~B})$, and $\mathrm{LPA}_{3}(\mathrm{C})$ are presented. The two agonists share a location with 18:1-LPA at the same hydrophobic pocket site but markedly differ in ionic and hydrogen bonds interaction mode. 
TABLE 2

Description of the $\mathrm{LPA}_{1-3}$ residues interacting with $\mathrm{CpX} / \mathrm{CpY} / O$ leoyl-LPA for the best docking poses

\begin{tabular}{lccc}
\hline Ballesteros-Weinstein Numbering & $\mathrm{hLPA}_{1}$ & $\mathrm{hLPA}_{2}$ & $\mathrm{LPA}_{3}$ \\
\hline Ionic pocket $(\mathrm{N}+)^{a}$ & & & \\
3.33 & $\mathrm{D} 129$ & $\mathrm{D} 112$ & $\mathrm{D} 110$ \\
5.43 & $\mathrm{~W} 210$ & $\mathrm{~W} 193$ & $\mathrm{~W} 191$ \\
Ionic pocket (PO4-) & & \\
7.36 & $\mathrm{~K} 294$ & $\mathrm{~K} 278$ & $\mathrm{R} 276$ \\
Hydrogen bond & & & $\mathrm{Y}$ \\
2.57 & $\mathrm{Y} 102$ & $\mathrm{Y} 85$ & $\mathrm{Q} 106$ \\
3.29 & $\mathrm{Q} 125$ & $\mathrm{Q} 108$ & $\mathrm{~L} 113$ \\
Hydrophobic pocket & & $\mathrm{L} 115$ \\
3.36 & $\mathrm{~L} 132$ & $\mathrm{~W} 254$ & $\mathrm{~L} 252$ \\
6.48 & $\mathrm{~W} 271$ & $\mathrm{~L} 261$ & $\mathrm{~L} 279$ \\
6.55 & $\mathrm{~L} 278$ & $\mathrm{~L} 281$ & $\mathrm{~A} 282$ \\
7.39 & $\mathrm{~L} 297$ & $\mathrm{~A} 284$ & \\
7.42 & $\mathrm{~A} 300$ & & \\
\hline
\end{tabular}

${ }^{a}$ Specific ionic interactions for $\mathrm{CpX} / \mathrm{CpY}$.

${ }^{b}$ Specific ionic interaction for Oleoyl-LPA. Other interactions are shared.

Barras, Geneviève Comte, Valérie Poignez, Françoise Demange, Marie-France Porquet, Olivier Crespin, Marie Claire Philippo, Thao Van Pham, Bruno Poirier, and many others and their respective teams who contributed significantly to the identification of LPAR as receptors for our agonists. We would also thank Paul Schaeffer, Fiona Ducrey, and Marco Meloni for proofreading of the manuscript.

\section{Authorship Contributions}

Participated in research design: Guillot, Le Bail, Paul, Philippo. Conducted experiments: Le Bail, Paul, Fourgous, Briand, Partiseti, Cornet.

Contributed new reagents or analytic tools: Philippo.

Performed data analysis: Guillot, Le Bail, Paul, Briand, Partiseti, Cornet, Philippo.

Wrote or contributed to the writing of the manuscript: Guillot, Le Bail, Partiseti, Cornet, Janiak, Philippo.

\section{References}

Baldwin JM (1993) The probable arrangement of the helices in G protein-coupled receptors. EMBO J 12:1693-1703.

Ballesteros JA and Weinstein H (1995) Integrated methods for the construction of three-dimensional models and computational probing of structure-function relations in G protein-coupled receptors. Methods Neurosci 25:366-428.

Balogh B, Pazmany T, and Matyus P (2015) Analysis of Edg-like LPA receptor-ligand interactions. Curr Pharm Des 21:3533-3547.

Bissantz C, Logean A, and Rognan D (2004) High-throughput modeling of human G-protein coupled receptors: amino acid sequence alignment, three-dimensional model building, and receptor library screening. J Chem Inf Comput Sci 44: 1162-1176.

Brünger AT, Adams PD, Clore GM, DeLano WL, Gros P, Grosse-Kunstleve RW, Jiang JS, Kuszewski J, Nilges M, Pannu NS, et al. (1998) Crystallography \& NMR system: a new software suite for macromolecular structure determination. Acta Crystallogr D Biol Crystallogr 54:905-921.

Choi JW, Lee CW, and Chun J (2008) Biological roles of lysophospholipid receptors revealed by genetic null mice: an update. Biochim Biophys Acta 1781:531-539.

Choi JW, Herr DR, Noguchi K, Yung YC, Lee CW, Mutoh T, Lin ME, Teo ST, Park KE, Mosley AN, et al. (2010) LPA receptors: subtypes and biological actions. Annu Rev Pharmacol Toxicol 50:157-186.

Chrencik JE, Roth CB, Terakado M, Kurata H, Omi R, Kihara Y, Warshaviak D, Nakade S, Asmar-Rovira G, Mileni M, et al. (2015) Crystal structure of antagonist Bound human lysophosphatidic acid receptor 1. Cell 161:1633-1643.

D’Souza K, Paramel GV, and Kienesberger PC (2018) Lysophosphatidic acid signaling in obesity and insulin resistance. Nutrients 10:399.

Dusaulcy R, Rancoule C, Grès S, Wanecq E, Colom A, Guigné C, van Meeteren LA, Moolenaar WH, Valet P, and Saulnier-Blache JS (2011) Adipose-specific disruption of autotaxin enhances nutritional fattening and reduces plasma lysophosphatidic acid. J Lipid Res 52:1247-1255.

Fells JI, Tsukahara R, Fujiwara Y, Liu J, Perygin DH, Osborne DA, Tigyi G, and Parrill AL (2008) Identification of non-lipid LPA $_{3}$ antagonists by virtual screening. Bioorg Med Chem 16:6207-6217.

Fredriksson R, Lagerström MC, Lundin LG, and Schiöth HB (2003) The G-proteincoupled receptors in the human genome form five main families. Phylogenetic analysis, paralogon groups, and fingerprints. Mol Pharmacol 63:1256-1272.

Friesner RA, Banks JL, Murphy RB, Halgren TA, Klicic JJ, Mainz DT, Repasky MP, Knoll EH, Shelley M, Perry JK, et al. (2004) Glide: a new approach for rapid, accurate docking and scoring. 1. Method and assessment of docking accuracy. J Med Chem 47:1739-1749.
González Gil I, Zian D, Vázquez-Villa H, Hernández-Torres G, Martinez RF, KhiarFernández N, Rivera R, Kihara Y, Devesa I, Mathivanan S, et al. (2020) A novel agonist of the type 1 lysophosphatidic acid receptor (LPA1), UCM-05194, shows efficacy in neuropathic pain amelioration. J Med Chem 63:2372-2390.

Halgren TA, Murphy RB, Friesner RA, Beard HS, Frye LL, Pollard WT, and Banks JL (2004) Glide: a new approach for rapid, accurate docking and scoring. 2. Enrichment factors in database screening. J Med Chem 47:1750-1759.

Halvorsen YD, Bond A, Sen A, Franklin DM, Lea-Currie YR, Sujkowski D, Ellis PN, Wilkison WO, and Gimble JM (2001) Thiazolidinediones and glucocorticoids synergistically induce differentiation of human adipose tissue stromal cells: biochemical, cellular, and molecular analysis. Metabolism 50:407-413.

Handford EJ, Smith D, Hewson L, McAllister G, and Beer MS (2001) Edg2 receptor distribution in adult rat brain. Neuroreport 12:757-760.

Kano K, Matsumoto H, Inoue A, Yukiura H, Kanai M, Chun J, Ishii S, Shimizu T, and Aoki J (2019) Molecular mechanism of lysophosphatidic acid-induced hypertensive response. Sci Rep 9:2662.

Kihara Y, Mizuno H, and Chun J (2015) Lysophospholipid receptors in drug discovery. Exp Cell Res 333:171-177.

Kiss GN, Fells JI, Gupte R, Lee SC, Liu J, Nusser N, Lim KG, Ray RM, Lin FT, Parrill AL, et al. (2012) Virtual screening for $\mathrm{LPA}_{2}$-specific agonists identifies a nonlipid compound with antiapoptotic actions. Mol Pharmacol 82:1162-1173.

Kornholt J, Sonne DP, Riis T, Sonne J, and Klarskov N (2019) Effect of imipramine on urethral opening pressure: a randomized, double-blind, placebo-controlled crossover study in healthy women. Neurourol Urodyn 38:1076-1080.

Malallah MA and Al-Shaiji TF (2015) Pharmacological treatment of pure stress urinary incontinence: a narrative review. Int Urogynecol $J$ 26:477-485.

Miloux B and Lupker JH (1994) Rapid isolation of highly productive recombinant Chinese hamster ovary cell lines. Gene 149:341-344.

Nilges M and Brünger AT (1991) Automated modeling of coiled coils: application to the GCN4 dimerization region. Protein Eng 4:649-659.

Nilges M, Clore GM, and Gronenborn AM (1988a) Determination of three-dimensional structures of proteins from interproton distance data by hybrid distance geometrydynamical simulated annealing calculations. FEBS Lett 229:317-324.

Nilges M, Clore GM, and Gronenborn AM (1988b) Determination of threedimensional structures of proteins from interproton distance data by dynamical simulated annealing from a random array of atoms. Circumventing problems associated with folding. FEBS Lett 239:129-136.

Ohta H, Sato K, Murata N, Damirin A, Malchinkhuu E, Kon J, Kimura T, Tobo M, Yamazaki Y, Watanabe T, et al. (2003) Ki16425, a subtype-selective antagonist for EDG-family lysophosphatidic acid receptors. Mol Pharmacol 64:994-1005.

Philippo C, Mougenot P, Braun A, Defosse G, Auboussier S, and Bovy PR (2000) Enantioselective sharpless dihydroxylation of vinylic aromatic heterocycles. Synthesis 1:127-134.

Philippo C, Auboussier S, Crespin O, Bovy P, and Courtemanche G (1998a) inventors, Synthelabo, assignee. $\alpha$-azacyclomethyl benzothiophene and $\alpha$-azacyclomethyl benzofuran derivatives, preparation and therapeutic application. W.O. patent 33,793. 1998 Aug 6 .

Philippo C, Orts MC, Crespin O, and Bovy P (1998b) inventors, Synthelabo, assignee. Benzylamine derivatives, their preparation and their application in therapeutics. W.O. patent 08,834. 1998 Mar 5.

Qian L, Xu Y, Hasegawa Y, Aoki J, Mills GB, and Prestwich GD (2003) Enantioselective responses to a phosphorothioate analogue of lysophosphatidic acid with LPA3 receptor-selective agonist activity. J Med Chem 46:5575-5578.

Qian L, Xu Y, Simper T, Jiang G, Aoki J, Umezu-Goto M, Arai H, Yu S, Mills GB, Tsukahara R, et al. (2006) Phosphorothioate analogues of alkyl lysophosphatidic acid as $\mathrm{LPA}_{3}$ receptor-selective agonists. ChemMedChem 1:376-383.

Rancoule C, Dusaulcy R, Tréguer K, Grès S, Attané C, and Saulnier-Blache JS (2014) Involvement of autotaxin/lysophosphatidic acid signaling in obesity and impaired glucose homeostasis. Biochimie 96:140-143.

Rozenblum GT, Kaufman T, and Vitullo AD (2014) Myelin basic protein and a multiple sclerosis-related MBP-peptide bind to oligonucleotides. Mol Ther Nucleic Acids 3:e192.

Saga H, Ohhata A, Hayashi A, Katoh M, Maeda T, Mizuno H, Takada Y, Komichi Y, Ota H, Matsumura N, et al. (2014) A novel highly potent autotaxin/ENPP2 
inhibitor produces prolonged decreases in plasma lysophosphatidic acid formation in vivo and regulates urethral tension. PLoS One 9:e93230.

Sakamoto K, Noguchi Y, Imazumi K, Ueshima K, Ohtake A, Takeda M, and Masuda N (2019) ASP6432, a type 1 lysophosphatidic acid receptor antagonist, reduces urethral function during urine voiding and improves voiding dysfunction. Eur $J$ Pharmacol 847:83-90.

Sakamoto K, Noguchi Y, Ueshima K, Yamakuni H, Ohtake A, Sato S, Ishizu K, Hosogai N, Kawaminami E, Takeda M, et al. (2018) Effect of ASP6432, a novel type 1 lysophosphatidic acid receptor antagonist, on urethral function and prostate cell proliferation. J Pharmacol Exp Ther 366:390-396.

Salous AK, Panchatcharam M, Sunkara M, Mueller P, Dong A, Wang Y, Graf GA Smyth SS, and Morris AJ (2013) Mechanism of rapid elimination of lysophosphatidic acid and related lipids from the circulation of mice. J Lipid Res 54:2775-2784. Serradeil-Le Gal C, Raufaste D, Double-Cazanave E, Guillon G, Garcia C, Pascal M, and Maffrand JP (2000) Binding properties of a selective tritiated vasopressin V2 receptor antagonist, [H]-SR 121463. Kidney Int 58:1613-1622.

Shankar G, Solow-Cordero D, Spenser JV, and Gluchowski C (2003) inventors, CERETEK LLC, assignee. Methods of treating conditions associated with an EDG receptor. W.O. patent 062,392. 2003 Jul 31
Shire D, Calandra B, Delpech M, Dumont X, Kaghad M, Le Fur G, Caput D, and Ferrara $\mathrm{P}$ (1996) Structural features of the central cannabinoid $\mathrm{CB}_{1}$ receptor involved in the binding of the specific $\mathrm{CB}_{1}$ antagonist SR 141716A. J Biol Chem 271:6941-6946.

Simon MF, Daviaud D, Pradère JP, Grès S, Guigné C, Wabitsch M, Chun J, Valet P, and Saulnier-Blache JS (2005) Lysophosphatidic acid inhibits adipocyte differentiation via lysophosphatidic acid 1 receptor-dependent downregulation of peroxisome proliferator-activated receptor gamma2. J Biol Chem 280:14656-14662

Terakado M, Suzuki H, Hashimura K, Tanaka M, Ueda H, Kohno H, Fujimoto T, Saga H, Nakade S, Habashita H, et al. (2016) Discovery of ONO-7300243 from a novel class of lysophosphatidic acid receptor 1 antagonists: from hit to lead. ACS Med Chem Lett 7:913-918

Yung YC, Stoddard NC, and Chun J (2014) LPA receptor signaling: pharmacology, physiology, and pathophysiology. J Lipid Res 55:1192-1214.

Address correspondence to: Dr. Etienne Guillot, Sanofi R\&D, 1, Ave. Pierre Brossolette, 91385 Chilly-Mazarin, France. E-mail: etienne.guillot@sanofi.com 